\title{
Heinrich von Kleist und die Revolutionen des Zusammenlebens
}

Die Macht, ja Gewalt, die von den Texten des am 18. Oktober 1777 in Frankfurt an der Oder geborenen und am 21. November 1811 freiwillig am Kleinen Wannsee aus dem Leben geschiedenen Heinrich von Kleist auszugehen pflegt, beginnt nicht selten mit dem Titel. So auch im Falle jenes Erzähltexts, der wie kein anderer aus der Feder Kleists auf fürwahr revolutionäre Weise die Frage nach Formen und Normen weltweiten Zusammenlebens stellt. Denn bereits mit dem paratextuellen Element der „Schwelle“1 setzt jenes eigentümliche Oszillieren ein, das die Gesamtheit einer Erzählung durchzieht, die erstmals in der Berliner Zeitschrift Der Freimüthige als Fortsetzungsgeschichte in den Ausgaben zwischen dem 25. März und dem 5. April des Jahres 1811 unter dem Titel Die Verlobung erschien. ${ }^{2}$ Was hat es mit dieser Verlobung auf sich und wer verlobt sich hier mit wem?

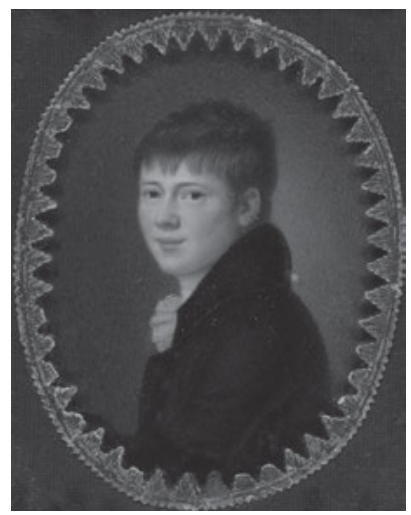

Abb. 14: Verlobungsbildnis von Heinrich von Kleist (Frankfurt an der Oder, 1777 - Berlin, 1811).

Schon die ursprüngliche Titelgebung dieses kurzen Erzähltexts wirft Fragen auf, die tief in die Problematik eines literarischen Schmuckstücks deutschsprachiger Prosa zu Beginn des 19. Jahrhunderts einführen. Denn um Verlobung geht es in diesem semantisch ungeheuer verdichteten Text zumindest auf den ersten Blick nicht: Eine Verlobung im eigentlichen Sinne als Ankündigung eines gemeinsamen

1 Vgl. Genette, Gérard: Seuils. Paris: Seuil 1987.

2 Kleist, Heinrich von: Die Verlobung in St. Domingo. Herausgegeben von Roland Reuß in Zusammenarbeit mit Peter Staengle. In (ders.): Sämtliche Werke. Berliner Ausgabe. Herausgegeben von Roland Reuß und Peter Staengle. Bd. II / 4. Basel - Frankfurt am Main: Stroemfeld - Roter Stern 1988.

Ә Open Access. (C) 2021 Ottmar Ette, publiziert von De Gruyter. (c) BY-NC-ND Dieses Werk ist lizensiert unter einer Creative Commons Namensnennung - Nicht-kommerziell - Keine Bearbeitung 4.0 International Lizenz. https://doi.org/10.1515/9783110703443-007 
Willens zur künftigen Eheschließung, die - wie Roland Reuß zurecht bemerkt hat - „ohne Einbeziehung von Öffentlichkeit undenkbar ist“, ${ }^{3}$ findet im gesamten Erzähltext nicht statt. Heinrich von Kleist, der seine eigene Verlobung mit der Generalstochter Wilhelmine von Zenge 1802 in schroffer Form und aus der Ferne aufgekündigt hatte, war dies gewiss bewusst. Der Text selbst unterstreicht diese Tatsache recht unverblümt ${ }^{4}$ und macht damit auf seine immanente Poetik aufmerksam: Diese steht von Anfang an im Zeichen einer Täuschung und Verstellung des Sinns, ${ }^{5}$ wie sie für das Gesamtwerk des Schriftstellers aus Frankfurt an der Oder charakteristisch ist - doch damit nicht genug!

Als der Erzähltext (nach einer weiteren, im Juni erfolgten Veröffentlichung als Fortsetzungsgeschichte in der Wiener Zeitschrift Der Sammler) im August 1811 im Berliner Verlag der Realschulbuchhandlung als Eröffnungstext des zweiten Bandes von Kleists Erzählungen erstmals in Buchform publiziert wurde, erweiterte ihr Verfasser die Titelwendung zu ihrer endgültigen Form: Die Verlobung in St. Domingo. Unter diesem Titel ist Kleists Erzählung in den Kanon der deutschen Nationalliteratur wie der ebenfalls in Entstehung begriffenen Weltliteratur der Zeit eingegangen.

Die scheinbar nur räumlich verortende Hinzufügung im Titel, die man gemeinhin in Forschung wie breiterer Öffentlichkeit „in Santo Domingo“ auszusprechen pflegt, deutet auf eine weitere Täuschung und Verstellung des Sinnes, der doch so evident, so augenscheinlich zu sein scheint. Denn die Abkürzung „St.“, die im Deutschen wie im Französischen gebräuchlich ist, kürzt nicht das spanische „Santo“ (Sto.) ab, was im Zusammenhang der Erzählung auch wenig Sinn machen würde, sondern verweist zurück auf den Namen der französischen Kolonie Saint-Domingue, jene „Perle der Karibik“, die über weite Strecken des 18. Jahrhunderts mit guten Gründen als die reichste und für ihre Herren wie ihr Mutterland ertragreichste Kolonie nicht nur der ,Neuen', sondern der gesamten Welt galt. Warum aber wählte Heinrich von Kleist diese Abkürzungsform?

Die von ihm nachträglich hinzugesetzte Ortsbezeichnung ist eine Hybridbildung, die man als „Sankt Domingo“, der Diegese aber wohl angemessener als „Saint Domingo“ aussprechen sollte, eine Form, durch welche die doppelte Zugehörigkeit der gesamten Insel in ihrem wirtschaftlich extrem intensiv genutzten

3 Reuß, Roland: „Die Verlobung in St. Domingo“ - eine Einführung in Kleists Erzählen. In: Berliner Kleist-Blätter (Basel) 1 (1988), S. 6.

4 Vgl. ebda.

5 Auf die paradoxe Einheit von Leben und Werk Heinrich von Kleists sowie auf „subtile Strategien der Verstellung“ hat gleich zu Beginn seiner Biographie hingewiesen Amann, Wilhelm: Heinrich von Kleist. Leben - Werk - Wirkung. Berlin: Suhrkamp 2011, S. 8. 
Westteil zum französischen, in ihrem größeren und extensiver genutzten Ostteil zum spanischen Kolonialsystem perfekt zur Geltung kommt. Die Zweiteilung der Insel Hispaniola war auch postkolonial von Bestand und spiegelt sich noch heute in den Bezeichnungen Haiti und República Dominicana für West- und Ostteil der Antilleninsel. Der Titel, dies zeigt sich bereits an dieser Stelle, hat es durchaus in sich und bedarf angesichts der raffinierten Verschlüsselungstechniken Heinrich von Kleists weiterer Klärung.

Die Insel wurde von Christoph Kolumbus im Spätjahr 1492 in einem europäischen Akt der Koppelung von Namensgebung und Besitzergreifung auf den Namen „Española“ getauft und ging unter der Bezeichnung „Hispaniola“6 in die Nomenklaturen geographischer Lehrwerke und Atlanten ein. Sie ist eine am Ausgang des 18. Jahrhunderts, mithin zum Zeitpunkt der Niederschrift des Textes, noch immer zwischen zwei europäischen Kolonialmächten aufgeteilte ,DoppelInsel', worauf bereits in den ersten Zeilen der Erzählung aufmerksam gemacht wird. Dort ist freilich die Rede von „dem französischen Antheil der Insel St. Domingo“, ${ }^{7}$ womit die wie stets bei Kleist raffiniert gestaltete Erzählerfigur ihre Leserschaft zum einen korrekt auf die Teilung der großen Antillen-Insel hinweist, zum anderen aber offenkundig in bewusster Täuschung von einer Insel namens „St. Domingo“ spricht, die es als solche - wie wir sahen - gar nicht gibt. Eine bloße Unachtsamkeit oder Gedankenlosigkeit Kleists? Sicherlich nicht!

Die mit dem zweiten Bestandteil des Titels identische Formulierung im Erzähltext weist uns auf eine semantische Verstellung, die in der Kombinatorik zweier Sprachen und zweier Herrschaftstraditionen ein semantisches Oszillieren in Gang setzt. Dieses macht zuallererst auf ein Drittes, Abwesendes aufmerksam: den auf indigene Wurzeln zurückgehenden präkolumbischen Namen Haiti, der mit der erkämpften Unabhängigkeit im Jahre 1804 auf der politischen Landkarte wieder erschien. So griffen die von Frankreich, der eigentlichen Führungsmacht der zweiten Phase beschleunigter Globalisierung, in die Karibik deportierten Sklaven auf jenen Namen zurück, den die von den Spaniern, der dominanten Führungsmacht der ersten Phase beschleunigter Globalisierung, ausgelöschte indigene Bevölkerung ihrer Insel einst gegeben hatte. Die schwarzen Sklaven knüpften damit an die gewaltsam unterdrückte präkolumbische Tradition der auf der Insel ursprünglich heimischen indigenen Bevölkerung an, deren ausfallende Arbeitskraft sie im spanischen Kolonialsystem seit Beginn des 16. Jahrhunderts

6 Zur Geschichte der Entdeckung und Kolonisierung der Insel Hispaniola vgl. Bernecker, Walther L.: Kleine Geschichte Haitis. Unter Mitarbeit von Sören Brinkmann und Patrick Ernst. Frankfurt am Main: Suhrkamp 1994, S. 11-22.

7 Kleist, Heinrich von: Die Verlobung in St. Domingo, S. 7. 
gleichsam als ,importierte Ureinwohner` ersetzten. Im hybriden Titel dieser im historischen Kontext der Haitianischen Revolution angesiedelten Erzählung ${ }^{8}$ sind Spanien wie Frankreich sprachlich mithin höchst präsent. Man könnte mit Blick auf die Lexik von einem dreisprachigen Titel sprechen, der Heinrich von Kleists einflussreicher deutschsprachiger Erzählung paratextuell vorangestellt ist.

In diesem hintergründigen Spiel mit dem Inselnamen, das ein Spiel der Täuschung und einer vom Text selbst signalisierten Verstellung ist, werden nicht nur unterschiedliche Sprachen und Bedeutungstraditionen, sondern auch zwei historische Epochen zusammengeführt. Wir dürfen sie als die erste, mit dem Jahr 1492 ihren frühen Höhepunkt erreichende Phase beschleunigter Globalisierung in deren Verlauf die iberischen Mächte Spanien und Portugal sich weite Teile des amerikanischen Kontinents aneigneten - und als die zweite Phase beschleunigter Globalisierung bezeichnen. Die letztgenannte stand in der zweiten Hälfte des 18. Jahrhunderts dabei ganz im Zeichen der Kolonialmächte Frankreich und England. ${ }^{9}$ Infolge dieses nicht allein politischen und ökonomischen, sondern auch sozialen und kulturellen Prozesses war die Karibik - und darin an erster Stelle das französische Saint-Domingue - zum weltweit am meisten verdichteten Raum einer von Europa ausgehenden Globalisierung geworden, die alle Bereiche des Lebens wie des Zusammenlebens in diesem geostrategisch zentralen Teil der amerikanischen Hemisphäre erfasste.

In der von Kleist gewählten Wendung St. Domingo werden diese beiden Phasen europäischer Expansion auf die vielleicht kürzeste und verdichtetste Weise nicht nur zusammengefügt, sondern auch zusammengefasst und zusammengedacht. Schon im paratextuellen Schwellenbereich des Erzähltextes handelt es sich um eines der für Kleists Schreiben charakteristischen Verdichtungswerke.

$8 \mathrm{Zu}$ der sich von Kleist herleitenden Textfiliation vgl. Uerlings, Herbert: Die Haitianische Revolution in der deutschen Literatur: H.v. Kleist - A.G.F. Rebmann - A. Seghers - H. Müller. In: Jahrbuch für Geschichte von Staat, Wirtschaft und Gesellschaft Lateinamerikas 28 (1991), S. 343389; sowie (ders.): Preußen in Haiti? Zur interkulturellen Begegnung in Kleists „Verlobung in St. Domingo“. In: Kleist-Jahrbuch (1991), S. 185-201.

9 Vgl. zu einer ersten Ausarbeitung dieser Periodisierung Ette, Ottmar: Weltbewusstsein. Alexander von Humboldt und das unvollendete Projekt einer anderen Moderne. Mit einem Vorwort zur zweiten Auflage. Weilerswist: Velbrück Wissenschaft 2020, S. $26 \mathrm{f}$; sowie (ders.): Wege des Wissens. Fünf Thesen zum Weltbewusstsein und den Literaturen der Welt. In: Hofmann, Sabine / Wehrheim, Monika (Hg.): Lateinamerika. Orte und Ordnungen des Wissens. Festschrift für Birgit Scharlau. Tübingen: Gunter Narr Verlag 2004, S. 169-184. Eine zusammenhängende Gesamtdarstellung findet sich in Ette, Ottmar: TransArea. Eine literarische Globalisierungsgeschichte. Berlin - Boston: Walter de Gruyter 2012. 
So ist offenkundig: Der Titel Die Verlobung in St. Domingo lässt sich als Titelfraktal verstehen, insofern in dieser Formel - die im Hinweis auf den Heiligen und der Hervorhebung des St. zugleich eine Dimension der Transzendenz eröffnet eine ungeheure semantische Verdichtung, eine historische Zusammenschiebung sowie die immanente Poetik der gesamten Erzählung zum Ausdruck kommen. Kleists Schreiben ist in einem fundamentalen Sinne modern und führt uns bereits tief ein in die weiteren Entwicklungsformen des zeitgenössischen Schreibens im 19. Jahrhundert.

Auf diese Tatsache macht auf Ebene der „écriture“ bereits die beobachtete enge Verzahnung von Titel und Incipit des Kleist’schen Erzähltextes aufmerksam, wie sie sich in den nicht anders als spektakulär zu nennenden Auftaktsätzen äußert:

Zu Port au Prince, auf dem französischen Antheil der Insel St. Domingo, lebte, zu Anfange dieses Jahrhunderts, als die Schwarzen die Weißen ermordeten, auf der Pflanzung des Hrn. Guillaume von Villeneuve, ein fürchterlicher alter Neger, Namens Congo Hoango. Dieser von der Goldküste von Afrika herstammende Mensch, der in seiner Jugend von treuer und rechtschaffener Gemüthsart schien, war von seinem Herrn, weil er ihm einst auf einer Überfahrt nach Kuba das Leben gerettet hatte, mit unendlichen Wohlthaten überhäuft worden. Nicht nur, dass Hr. Guillaume ihm auf der Stelle seine Freiheit schenkte, und ihm, bei seiner Rückkehr nach St. Domingo, Haus und Hof anwies; er machte ihn sogar, einige Jahre darauf, gegen die Gewohnheit des Landes, zum Aufseher seiner beträchtlichen Besitzung, und legte ihm, weil er nicht wieder heirathen wollte, an Weibes Statt eine alte Mulattinn, Namens Babekan, aus seiner Pflanzung bei, mit welcher er durch seine erste verstorbene Frau weitläufig verwandt war. Ja, als der Neger sein sechzigstes Jahr erreicht hatte, setzte er ihn mit einem ansehnlichen Gehalt in den Ruhestand und krönte seine Wohlthaten noch damit, dass er ihm in seinem Vermächtniß sogar ein Legat auswarf; und doch konnten alle diese Beweise von Dankbarkeit Hrn. Villeneuve vor der Wuth dieses grimmigen Menschen nicht schützen. ${ }^{10}$

Bereits der erste Satz von Kleists Meistererzählung blendet eine räumliche und zeitliche Situierung und Kontextualisierung ein, in der - für das Schaffen des in Frankfurt an der Oder geborenen Autors außergewöhnlich - die nur wenige Jahre zurückliegenden Ereignisse der Haitianischen Revolution als unmittelbarer historischer und geographischer Referenzrahmen dienen. War Bernardin de SaintPierres Paul et Virginie im Jahr der Französischen Revolution erstmals separat in Buchform erschienen, so folgt Kleists Die Verlobung in St. Domingo nach Ende des haitianischen Revolutionsprozesses, der nur wenig später als die Revolution in Frankreich eingesetzt hatte.

10 Kleist, Heinrich von: Die Verlobung in St. Domingo, S. $7 \mathrm{f}$. 
Die Erzählerstimme, die wir nicht - wie immer wieder zu beobachten - mit dem realen textexternen Autor verwechseln dürfen, nimmt in diesem Incipit eine unübersehbar parteiische Position insofern ein, als Aufstand und Revolution gegen das auf Sklaverei basierende Plantagensystem als ein Zeit- und KonfliktRaum in Szene gesetzt werden, in dem schlicht „die Schwarzen die Weißen“ ermordet hätten. ${ }^{11}$ Diese als solche deutlich markierte anfängliche SchwarzweißAufnahme präsentiert damit die komplexe historische Situation als die eines Rassenkrieges, in welchem die Weißen zu Opfern der Schwarzen geworden seien. Dass dies eine höchst parteiische Sichtweise der ersten Phase der Haitianischen Revolution ist, braucht an dieser Stelle nicht betont zu werden.

Kein Zweifel: Der historische Hintergrund der Ereignisse im Kontext der Haitianischen Revolution lässt sich als größter anzunehmender Unfall des Zusammenlebens bezeichnen, wobei ganz selbstverständlich davon auszugehen ist, dass der zuvor herrschende Zustand der Konvivenz auf einer extremen kolonialen Ausbeutung und brutalen Unterdrückung beruhte, wie sie die europäischen Herrschaftssysteme seit Beginn der ersten Globalisierungsphase charakterisierte. Die Ereignisse der Haitianischen Revolution waren lediglich eine Antwort auf diese jahrhundertelange unmenschliche Ausplünderung und Bevormundung durch den europäischen Kolonialismus.

Das revolutionäre Frankreich reagierte auf die nicht weniger revolutionären Entwicklungen in seiner Kolonie mit ständig neuen Kurswechseln und Dekreten. Die Société des Amis des Noirs bildete nur einen Pol innerhalb höchst widerstreitender Standpunkte im kolonialen Mutterland, das nun auch zum Mutterland der Revolution geworden war. Doch als der an die Macht gekommene Napoleon schließlich versuchte, mit der Entsendung einer von General Leclerc befehligten und am 1. Februar 1802 in Saint-Domingue gelandeten Expeditionsarmee unter massivstem Einsatz französischer Truppen die reiche Kolonie für Frankreich zurückzuerobern und die Sklaverei wiedereinzuführen, setzten sich die Revolutionäre hartnäckig und entschlossen zur Wehr. Die letzte Phase des an überraschenden Wendungen reichen Unabhängigkeitskampfes des künftigen Haiti hatte begonnen, und sie sollte zur endgültigen Lösung des blutigen Konflikts führen. ${ }^{12}$

11 Ebda., S. 7. Zur Frage nach dem Rassismus Kleists vgl. Loster-Schneider, Gudrun: Toni, Babekan und Homi Bhabha? Zu Problemen kultureller und ästhetischer Hybridisierung in Heinrich von Kleists „Die Verlobung in St. Domingo“. In: Lüsebrink, Hans-Jürgen (Hg.): Das Europa der Aufklärung und die außereuropäische koloniale Welt. Göttingen: Wallstein Verlag 2006, S. 231; dort finden sich auch zahlreiche weiterführende bibliographische Angaben.

12 Vgl. hierzu auch Nesbitt, Nick: The Haitian Revolution and the Globalization of the Radical Enlightenment. In: Ette, Ottmar (Hg.): Caribbean(s) on the Move - Archipiélagos literarios del 
Nicht umsonst ist in den Formulierungen des Incipit von der Grausamkeit der napoleonischen Truppen, die rücksichtslos gegen die Aufständischen vorgingen und diese gnadenlos massakrierten, nicht im Mindesten die Rede. In Europa, vor allem aber in den nahe Haiti liegenden europäischen Kolonien der Karibik, wurden allein die Massaker an den Weißen bekannt und aufgeregt diskutiert. Als ein an den Weißen verübtes Blutbad, ja als gefährlich auflodernder „Weltbrand“ erschien in der zeitgenössischen europäischen Presse jener „Negeraufstand“, der als die erste erfolgreiche Sklavenrevolution in die Weltgeschichte eingehen und das erste politisch unabhängige Land des entstehenden „Lateinamerika“ - diese Bezeichnung findet sich erst seit Mitte des 19. Jahrhunderts ${ }^{13}$ - bilden sollte. Die „Negersklaven von Haiti“ hatten, wie man mit Hans Christoph Buch formulieren könnte, „Robespierre beim Wort“ genommen ${ }^{14}$ und sich ihre eigene Unabhängigkeit im Zeichen erhoffter „Liberté“, „Egalité“ und „Fraternité“ erkämpft. Wie viele seiner Zeitgenossen war Heinrich von Kleist - wie noch genauer erläutert werden soll - mit den Ereignissen auf der Insel Hispaniola selbstverständlich gut vertraut, auch wenn wir eher wenig über seine eigene Position zu den Ereignissen auf der ehemals reichsten europäischen Kolonie Saint-Domingue wissen.

Auch wenn die Haitianische Revolution über lange Zeit hinweg, bis in unsere Gegenwart hinein, kaum einmal Eingang fand in die Entfaltung westlicher Revolutionstheorien, ${ }^{15}$ wurden die oft als „Empörung“ abqualifizierten Ereignisse aus Hispaniola doch rasch zu einem Paradigma ${ }^{16}$ und zum Ausnahmefall einer Katastrophe. Diese löste nicht nur im karibischen Raum, sondern auch in den kolonialen Mutterländern Europas bei den Weißen Furcht und Schrecken aus. Der ,Fall Haiti“ ist mit Blick auf die vorherrschende westliche Revolutionstheorie mehr als

Caribe. A TransArea Symposium. Frankfurt am Main - New York - Oxford: Peter Lang Verlag 2008, S. 40-59.

13 Vgl. hierzu Jurt, Joseph: Entstehung und Entwicklung der Lateinamerika-Idee. In: Lendemains (Köln) 27 (1982), S. 17-26.

14 Buch, Hans Christoph: Die Scheidung von San Domingo. Wie die Negersklaven von Haiti Robespierre beim Wort nahmen. Berlin: Verlag Klaus Wagenbach 1976.

15 Vgl. hierzu Müller, Gesine: Die koloniale Karibik zwischen Bipolarität und Multirelationalität. Transferprozesse in hispanophonen und frankophonen Literaturen. Habilitationsschrift an der Philosophischen Fakultät der Universität Potsdam, Potsdam 2011, S. $128 \mathrm{f}$.

16 Vgl. u.a. Bremer, Thomas: Haiti como paradigma. La emancipación de los esclavos en el Caribe y la literatura europea. In: López de Abiada, J.M. / Peñate Rivero, J. (Hg.): Perspectivas de comprensión y explicación de la narrativa latinoamericana. Grandes Seminarios de Travers. Bellinzona: Ed. Casagrande 1982, S. 43-66. Auf die außerordentliche Präsenz der Ereignisse auf Saint-Domingue sowie der Unabhängigkeit Haitis gerade auch im deutschsprachigen Raum etwa rund um die Zeitschrift Minerva machte ausführlich aufmerksam Buck-Morss, Susan: Hegel and Haiti. In: Critical Inquiry (Chicago) 26 (Summer 2000), S. 821-865. 
problematisch. In ihrem Grundlagenwerk On Revolution ${ }^{17}$ verzichtete selbst eine für ihre denkerische Integrität so bekannte Hannah Arendt, die in neuerer Zeit auf Grund rassistischer Passagen in ihren Schriften ins Gerede gekommen ist, auf eine Erwähnung Haitis und der Haitianischen Revolution. Kolonialismus und Sklaverei sind über lange Zeiträume in der Theorie der Moderne - und speziell auch in der Revolutionstheorie - lediglich als Randphänomene oder gar Störfaktoren aufgefasst worden. ${ }^{18}$ Wir sollten also vorsichtig damit sein, den Rassismus früherer Generationen zu beklagen und anzuprangern, wenn sich selbst noch in unseren heutigen Wissenschaften nicht geringe Restbestände davon vorfinden lassen.

Doch eine wissenschaftliche Hinwendung zur Haitianischen Revolution ist in jüngster Zeit unverkennbar und im Übrigen nicht nur wohlbegründet, sondern dringend notwendig. ${ }^{19}$ Die durchaus schmerzhafte und schwierige „Geburt Haitis“20 war ein überaus vielschichtiger, zugleich aber notwendig gewaltsamer Prozess, der in Europa, aber auch in den Nachbarkolonien der Karibik in blutroten Farben dargestellt wurde, mussten die weißen Herrschaftseliten doch befürchten, ähnlich wie in Saint-Domingue von einer zahlenmäßig überlegenen Bevölkerung schwarzer Sklaven hinweggefegt und bestenfalls ins Exil gezwungen zu werden. Überall auf den umliegenden Inseln begann man, Vorsichtsmaßnahmen zu ergreifen, damit sich eine - aus Sicht der weißen Pflanzer-Eliten - derartige Katastrophe wie in Haiti kein zweites Mal ereignen konnte.

Es erscheint vor diesem Hintergrund als folgerichtig, dass Heinrich von Kleists Erzähler eine derartige Sichtweise als verbreitete Meinung gleichsam bei seiner weißen Leserschaft voraussetzt, um daraus das Schreckensbild eines urplötzlich implodierenden Zusammenlebens zu zeichnen. Dass dieses Zusammenleben ein koloniales und mit den Mitteln brutaler Sklaverei erzwungenes war, bleibt ungesagt. Die Verlobung in St. Domingo erzählt aus großer zeitlicher Nähe vom Kollaps der Konvivenz im kolonialen Kontext, die - wie betont - auf den Regeln eines gnadenlos funktionierenden Kastenwesens beruhte. Wir hatten dieses Kastenwesen bei Bernardin de Saint-Pierre in seiner idyllischen Variante fried- und verständnisvoller Konvivenz von Sklaven und ihren (in diesem Falle zumeist weiblichen) Sklavenbesitzern erlebt. Bei Heinrich von Kleist ist diese Idylle - wo es sie denn

17 Vgl. Arendt, Hannah: On Revolution. New York: The Viking Press 1963.

18 Vgl. hierzu Fischer, Sibylle: Modernity Disavowed. Haiti and the Cultures of Slavery in the Age of Revolution. Durham - London: Duke University Press 2004, S. 8 f.

19 Vgl. hierzu u. a. Bongie, Chris: Friends and Enemies. The Scribal Politics of Post/Colonial Literature. Liverpool: Liverpool University Press 2008.

20 Bernecker, Walther L.: Kleine Geschichte Haitis, S. 37. 
gab - unvermittelt zusammengebrochen: Leben, Erleben und erhofftes Überleben einer kleinen Gruppe Weißer, die sich nach Port-au-Prince durchzuschlagen versucht, stehen in seiner Erzählung im Vordergrund der literarischen Darstellung.

Heinrich von Kleist hat diese Problematik des Zusammenlebens von Beginn an behutsam in seinen Text eingefügt. So signalisiert schon das erste Verb der Erzählung (,lebte“) die entscheidende Bedeutungsebene des Lebens und der Konvivenz, die ja in aller Deutlichkeit auch in die höchst durchdachte Titelgebung eingeflossen ist. Denn was könnte eine Verlobung anderes sein als das formalisierte Versprechen auf ein künftig gemeinsam angestrebtes Zusammenleben? Auf die prospektive Dimension des Lexems „Verlobung“ wie auf die Perspektivik des Künftigen wird in diesem Zusammenhang noch wiederholt zurückzukommen sein. Denn eben dieses Versprechen auf Zukunft wird in der Komplexität der sich anbahnenden Ereignisse mit ihren Verständnissen und Missverständnissen blutig von den Protagonisten der Erzählung selbst gekappt.

Wenn also die Isotopie des Lebens und der Konvivenz geradezu unübersehbar - und doch in aller Regel übersehen - Titel und Auftakt von Die Verlobung in St. Domingo dominiert, so geschieht dies nicht, ohne dass auch die Herrschaftsverhältnisse zwischen Herren und Sklaven in aller Eindrücklichkeit vorgeführt werden würden. Auch hier bedient sich die Erzählerfigur eines erzählerischen Kunstgriffs, insofern die bei einem europäischen Lesepublikum zu erwartende Einschätzung der kolonialen Hierarchie und Asymmetrie in den Text als gleichsam ,selbstverständliche' Setzung miteingegeben wird. Es ist eine Setzung, deren Aufkündigung das blanke Ent-Setzen hervorruft. Denn Guillaume von Villeneuve auch hier handelt es sich wiederum um eine zweisprachige Namensgebung - wird in mehrfacher Wiederholung als „Herr“ tituliert, während ein „fürchterlicher alter Neger, Namens Congo Hoango“21 keinerlei Anspruch auf eine respektvolle Anrede und Titulierung besitzt. Die Makrohistorie ist bis in die letzten Verästelungen der Erzählung sprachlich übersetzt und zeugt von einer außerordentlichen erzählerischen Raffinesse des Verfassers.

Auch im Falle Congo Hoangos ist die von Kleist gewählte Namensgebung aufschlussreich, handelt es sich bei diesem Schwarzen doch nicht um einen auf Hispaniola geborenen Sklaven, sondern um einen aus Afrika deportierten „Mensch“, in dessen Namen zwei Flüsse, der Congo und der Huang-he, also ein afrikanischer und ein asiatischer Strom, in einem Doppelnamen zusammenfließen. Dabei blendet die chinesische Bezeichnung für den „Gelben Fluss“ versteckt - wenn auch für die Benutzer zeitgenössischer Nachschlagewerke erkenn-

21 Kleist, Heinrich von: Die Verlobung in St. Domingo, S. 7. 
bar $^{22}$ - erstmals die Farbe Gelb (chinesisch „huang“) in den Text ein. In das mit der Namensgebung „Congo“ aufgerufene Schwarze mischt sich hier auf hintergründige Weise das Gelbe als ein Drittes, das sich in dem von Kleists Erzählung bald schon explizit in Gang gesetzten Farbenspiel zwischen dem Weißen und dem Schwarzen platziert. Wie immer wusste Kleist sehr genau, was er mit der Einführung der Farbe Gelb erzählerisch tat.

Congo Hoango ist eine sehr komplex gestaltete Figur. Er wird uns in der Folge zunächst als Lebensretter seines französischen Besitzers und unmittelbar danach als Mörder desselben vorgestellt. Congo Huango gibt und nimmt Leben. Dass Kleist die Rettung des Herrn durch seinen Sklaven ausgerechnet bei einer Überfahrt nach Kuba geschehen lässt, also genau jenem Übersetzen zwischen den beiden Großen Antillen, das den späteren Fluchtweg der Pflanzer-Aristokratie Saint-Domingues auf die Nachbarinsel vorwegnimmt, ist keineswegs dem Zufall zu verdanken. Denn diese vektorielle Bahnung oder Einschreibung des künftigen Exodus der Vertreter einer hinweggefegten Herrschaftsstruktur übersetzt die Leben rettende Aktion des Schwarzen wenig später in ein todbringendes Handeln, indem Villeneuve und seiner Familie keine Chance mehr gegeben wird, auf demselben Weg die rettende Flucht auf die Nachbarinsel Kuba anzutreten. Congo Huango ist Herr über Leben und Tod, und er verfolgt ein Ziel: Rache an den Weißen.

Die archipelische Vielverbundenheit der kolonialen Karibik erscheint bereits auf Ebene des Personals der Kleist'schen Erzählung in aller Deutlichkeit: So ist die Mulattin Babekan von einem Weißen in Santiago de Kuba gezeugt worden; ihre Tochter Toni erblickte in Europa das Licht der Welt; Congo Hoango wurde aus Afrika deportiert; Villeneuve kommt aus Frankreich; Gustav oder Strömli stammen aus der Schweiz - die Reihe der Kleist'schen Figuren ließe sich leicht fortsetzen. Diese Vielverbundenheit jedoch wird in der Haitianischen Revolution mit nicht nur wirtschaftlich weitreichenden Folgen unterbrochen: Die Inselwelt wird tendenziell zu einer Insel-Welt. ${ }^{23}$ Als solche führt uns der Kleist'sche Erzähler die „Insel“ St. Domingo auch vor.

Werden sie auch affirmativ vom Erzähler vorgetragen, so sind die „Wohlthaten“ des Herrn von Villeneuve doch Gunstbeweise eines Sklavenhalters, die

22 Vgl. hierzu das Zitat aus Zedlers Großem Vollständigen Universallexicon aller Wissenschaften und Künste in Reuß, Roland: „Die Verlobung in St. Domingo“ - eine Einführung in Kleists Erzählen, S. 18.

23 Vgl. zu dieser Unterscheidung Ette, Ottmar: Von Inseln, Grenzen und Vektoren. Versuch über die fraktale Inselwelt der Karibik. In: Braig, Marianne / Ette, Ottmar / Ingenschay, Dieter / Maihold, Günther (Hg.): Grenzen der Macht - Macht der Grenzen. Lateinamerika im globalen Kontext. Frankfurt am Main: Vervuert Verlag 2005, S. 135-180. 
dem System einer extrem profitorientierten Sklavenwirtschaft, für das die französische Zuckerkolonie Saint-Domingue paradigmatisch stand, ein menschlicheres Antlitz zu geben suchten. Sie sind nicht Zeichen eines wie auch immer gearteten ,Ausstiegs‘ aus dem Sklavenhaltersystem, sondern dessen Affirmation, ja dessen Bedingung. Nicht zufällig sollten es gerade die französischen Zuckeroligarchen aus Saint-Domingue sein, die nach ihrer Flucht auf die Nachbarinsel schon bald das in spanischem Besitz befindliche Kuba in den weltweit größten Zuckerproduzenten verwandelten.

Sie vollzogen diese ökonomische und soziale Transformation ganz bewusst und nicht ohne dabei maßgeblich dafür zu sorgen, dass die ,Einfuhr‘ schwarzer Sklaven für den Anbau von Zuckerrohr und Kaffee sich binnen weniger Jahrzehnte vervielfachte und neue Techniken der Ausbeutung - die man wohl nur im Zeichen einer zynischen Vernunft als ,Modernisierung bezeichnen kann - implementiert wurden. ${ }^{24}$ So setzte das Knowhow der Führungsmacht der zweiten Phase beschleunigter Globalisierung ins Kolonialreich Spaniens über, eine Tatsache, ohne welche die Ausnahmestellung Kubas im 19. Jahrhundert - ebenso hinsichtlich des beobachtbaren wirtschaftlichen Aufstiegs wie des Verbleibs der Insel im spanischen Kolonialbesitz - kaum adäquat zu verstehen ist.

So nimmt die von Kleist eingeblendete Überfahrt nach Kuba eine historische Entwicklung vorweg, die 1811, also ein Jahrsiebt nach der Unabhängigkeit Haitis, bereits in ihren wirtschaftlichen und gesellschaftlichen, aber auch in ihren kulturellen Folgen deutlich absehbar war. Die in die Erzählung eingeflochtene Freilassung von Congo Hoango verwandelte zugleich den schwarzen Sklaven auf Geheiß seines Herrn in einen Aufseher, der selbstverständlich auch die Sklaven seines Herren zu ,beaufsichtigen' hatte, Aufgaben also, die ihn in eine Position zwischen seinem Herrn und den ihm untergeordneten Sklaven einrückten. Dabei übersetzte die von Villeneuve geschaffene Verbindung mit der Mulattin Babekan diese Zwischenstellung zusätzlich in eine soziokulturell verankerte Skala der Hautfarben zwischen schwarz und weiß. Congo Hoango ist kein einfacher schwarzer Sklave: Er ist es im Kolonialsystem von Saint-Domingue als „dominé dominant“ gewohnt, selbst Befehle zu erteilen und deren Ausführung verbunden mit einem reichen Portfolio an Strafen zu überwachen.

Der freigelassene Sklave aber dankte es der Dankbarkeit seines Herren nicht, sondern jagte - in der Folge all jener politischen Ereignisse, welche durch die

24 Zur Entwicklung von Sklavenwirtschaft und Zuckerproduktion an der Wende vom 18. zum 19. Jahrhundert in Kuba vgl. die klassische Studie von Moreno Fraginals, Manuel: El Ingenio. El complejo económico social cubano del azúcar. Bd. 1: 1760-1860. La Habana: Comisión Nacional Cubana de la UNESCO 1964. 
„unbesonnenen Schritte des National-Convents“ erst ausgelöst worden seien „seinem Herrn die Kugel durch den Kopf“, wohlgemerkt: „eingedenk der Tyrannei, die ihm seinem Vaterlande entrissen hatte“. ${ }^{25}$ Der Herr wird in diesem Sinne als Repräsentant eines ebenso tyrannischen wie lukrativen Systems transatlantischen Sklavenhandels gerichtet, das sich im Kontext der zweiten Phase beschleunigter Globalisierung sehr stark weiterentwickelt und die intensivsten und menschenverachtendsten Formen der Ausbeutung des Menschen durch den Menschen noch ,modernisiert ${ }^{\star}$ und damit auf die Spitze getrieben hatte. ${ }^{26}$ Villeneuve stirbt als Repräsentant eines weltweit agierenden französischen Kolonialsystems, das zeitgenössisch nur noch vom britischen Empire übertroffen wurde europäische Kolonialismen, die in ihrer Menschenverachtung grenzenlos waren und bis heute nicht entschuldbar sein können. Gleichwohl ist es anzuerkennen, dass sich Frankreichs Staatspräsident Emmanuel Macron in Afrika für die Gräuel des französischen Kolonialismus offiziell entschuldigt hat. Von britischer Seite fehlt nach meinem Wissensstand jegliches Zeichen für ein Bewusstsein dafür: Man schwelgt bis heute lieber im Glanze eines glorreichen „British Empire“.

Vergessen wir an dieser Stelle nicht, wie sehr sich Heinrich von Kleist in einem Brief an Rühle von Lilienstern im Dezember 1805 darüber empört hatte, wie „aus dem ganzen cultivierten Theil von Europa ein einziges großes System von Reichen“27 in Entstehung begriffen sei. Dieses befinde sich unter der Führung Napoleons - der sich im Dezember 1804 selbst die Kaiserkrone aufsetzte - in völliger Abhängigkeit. Und nicht umsonst endete dieser Brief mit der Hoffnung auf einen Tyrannenmord in Formulierungen, die der Rede von der Tyrannei des Sklavenhandels in Die Verlobung in St. Domingo sehr nahe kommen: „Warum sich nur nicht Einer findet, der diesem bösen Geiste der Welt die Kugel durch den Kopf jagt. “28 Den befreiten Sklaven von Haiti hätte man dies nicht zweimal sagen müssen.

Vor dem Hintergrund dieses in seiner ganzen Brutalität am eigenen Körper erlebten Systems war für Congo Hoango an ein friedliches Zusammenleben mit den Weißen nicht länger zu denken:

25 Kleist, Heinrich von: Die Verlobung in St. Domingo, S. 8.

26 Zum transatlantischen Sklavenhandel und seiner Geschichte vgl. Zeuske, Michael: Handbuch Geschichte der Sklaverei. Eine Globalgeschichte von den Anfängen bis zur Gegenwart. 2., überarbeitete und erweiterte Auflage. 2 Bände. Berlin - Boston: Walter de Gruyter 2019.

27 Kleist, Heinrich von: Sämtliche Werke und Briefe in vier Bänden. Herausgegeben von IlseMarie Barth, Klaus Müller-Salget, Stefan Ormanus und Hinrich C. Seeba. Frankfurt am Main: Deutscher Klassiker Verlag 1987 ff, Bd. IV, S. 352.

28 Ebda. 
[...] er steckte das Haus, worein die Gemahlinn desselben mit ihren drei Kindern und den übrigen Weißen der Niederlassung sich geflüchtet hatte, in Brand, verwüstete die ganze Pflanzung, worauf die Erben, die in Port au Prince wohnten, hätten Anspruch machen können, und zog, als sämmtliche zur Besitzung gehörige Etablissements der Erde gleich gemacht waren, mit den Negern, die er versammelt und bewaffnet hatte, in der Nachbarschaft umher, um seinen Mitbrüdern in dem Kampfe gegen die Weißen beizustehen. ${ }^{29}$

So werden etwa in der Rede von der Tyrannei in und unter der Stimme des Erzählers in Die Verlobung in St. Domingo schon auf den ersten Seiten andere Stimmen hörbar, die nicht nur vom Mord der Schwarzen an den Weißen, sondern auch von der Tyrannei eines global agierenden und auf Sklaverei basierenden Wirtschaftssystems der Zuckerrohrplantagen berichten. Heinrich von Kleist gibt uns diese unterschiedlichen Stimmen in einem Text, der hochgradig polyphon ist, auf diskrete Weise zu Gehör. Zu diesen zeitgenössischen Stimmen gehörte auch ein weitgereister preußischer Landsmann Heinrich von Kleists, der anders als dieser zwar Frankreich nicht ablehnend gegenüberstand, wohl aber tiefgreifende Zweifel an dem immer rücksichtsloser ,modernisierten' Kolonialsystem und dessen Sklavenwirtschaft äußerte. Wir sollten uns mit ihm und seinen zeitgenössischen Kontexten kurz beschäftigen, um ein genaueres Gefühl für das an der Schwelle zum 19. Jahrhundert nicht nur Denkbare, sondern auch Schreib- und Publizierbare zu bekommen.

Heinrich von Kleist war sicherlich mit Aspekten jenes sogenannten „Disputs um die Neue Welt“ ${ }^{* 30}$ vertraut, der von den 1768 und 1769 in Berlin veröffentlichten Recherches philosophiques sur les Américains des Cornelius de Pauw ausgegangen war und einen ersten Höhepunkt mit der „Berliner Debatte“ erreichte. Letztere entzündete sich an Antoine-Joseph Pernetys an der Preußischen Akademie gehaltenen und gegen de Pauw gerichteten Vortrag vom 7. September 1769. ${ }^{31}$ Es handelt sich um Debatten von großer geschichtlicher Reichweite, die einen langen historischen Vorlauf seit Beginn der ersten Phase beschleunigter Globalisierung besaßen und selbst an der Wende zum 20. Jahrhundert noch längst nicht abge-

29 Kleist, Heinrich von: Die Verlobung in St. Domingo, S. 8 f.

30 Vgl. hierzu das Standardwerk von Gerbi, Antonello: La Disputa del Nuovo Mondo. Storia di una Polemica: 1750-1900. Nuova edizione a cura di Sandro Gerbi. Mailand - Neapel: Riccardo Ricciardi Editore 1983.

31 Vgl. hierzu den Text von Pernety, Antoine-Joseph: Dissertation sur l'Amérique et les Naturels de cette partie du monde. In: Mr. de $\mathrm{P}^{\star \star \star}$ [Pauw, Cornelius de]: Recherches philosophiques sur les Américains ou Mémoires intéressants pour servir à l'Histoire de l'Espèce Humaine. Avec une Dissertation sur l'Amérique \& les Américains, par Dom Pernety. Et la Défense de l'Auteur des Recherches contre cette Dissertation. Berlin: Chez Georges Jacques Decker, Imp. du Roi 1770. 
golten waren. Noch in Hegels Vorlesungen über die Weltgeschichte klingen lange Jahrzehnte später die Auseinandersetzungen nach, die nicht allein zwischen europäischen, sondern gerade zwischen neuweltlichen und altweltlichen Philosophen über Jahrzehnte ausgetragen wurden. Auch in Die Verlobung in St. Domingo lassen sich deutliche Spuren dieser bisweilen hitzig geführten Debatten und ihrer Ergebnisse finden, handelte es sich doch um Auseinandersetzungen, die mit großer Schärfe in einer aufgeklärten wie auch nicht-aufgeklärten Öffentlichkeit in Europa geführt wurden.

Expliziter freilich sind aus diegetischen Gründen in diesem Erzähltext die politischen Debatten im benachbarten Frankreich konturiert. Der bereits erwähnte Hinweis des Erzählers auf die „unbesonnenen Schritte des National-Convents“32 verweist über die singulären Debatten und Dekrete der verschiedenen durch die Französische Revolution geschaffenen Verfassungsorgane hinaus auf die politischen Auseinandersetzungen in Paris, die von größter Bedeutung für die administrativen Rahmenbedingungen einer Konvivenz der unterschiedlichsten sozialen und ethnischen Gruppen in den französischen Kolonien waren.

Heinrich von Kleist war über all diese Entwicklungen wohlunterrichtet. Nicht nur die vom 7. bis 15. Mai 1791 in der „Constituante“ geführte große Kolonialdebatte, sondern vor allem die am 4. Februar 1794 vom Nationalkonvent beschlossene Abschaffung der Sklaverei in den Kolonien führten zu unmittelbaren Reaktionen auch und gerade in der französischen Karibik. Diese Reaktionen beleuchten die Schnelligkeit politischer wie administrativer Umsetzungen, wie sie die transatlantischen Beziehungen in der zweiten Phase beschleunigter Globalisierung charakterisierten. Was in Paris öffentlich diskutiert wurde, besaß unmittelbare Auswirkungen auf die jeweiligen Kolonialgebiete, stieß aber auch auf sofortige Reaktionen in den Kolonien selbst. Nicht umsonst verfügte die Karibik als Zone verdichtetster Globalisierung über sehr rasche Verbindungen, welche die Kolonien mit ihren jeweiligen europäischen Mutterländern in engstem Austausch über das atlantische Längstal hinweg hielten. Dies galt auch und gerade für die französischen Kolonien zum Zeitpunkt der Französischen Revolution.

Umfassende Analysen der demographischen Grundlagen wie der wirtschaftlichen Auswirkungen dieser Prozesse wurden erst mit deutlichem zeitlichem Abstand in Untersuchungen erzielt, die sich aus globalisierender Perspektive der Gesamtheit jenes Raumes zuwandten, den wir heute als „Greater Caribbean“ bezeichnen. In seinem separat erstmals 1826 veröffentlichten und im Kontext seines französischsprachigen Reiseberichts über den gemeinsam mit Aimé Bonp-

32 Kleist, Heinrich von: Die Verlobung in St. Domingo, S. 8. 
land unternommenen Voyage aux Régions équinoxiales du Nouveau Continent ${ }^{33}$ entstandenen Essai politique sur l'île de Kuba machte Alexander von Humboldt immer wieder auf die extrem unmenschlichen Produktionsbedingungen auf Saint-Domingue aufmerksam, wobei er seine Überlegungen mit umfangreichem statistischem Material unterlegte. ${ }^{34}$ Dabei hatte Humboldt bereits 1804 - wie wir heute aus einem in der Jagiellonen-Bibliothek zu Krakau aufgetauchten Manuskript wissen - eine Sichtweise der Insel Kuba sowie der gesamten Karibik entwickelt, die keinen Zweifel an seinen bereits damals vorhandenen abolitionistischen, gegen den Fortbestand der Sklaverei gerichteten Auffassungen zulassen. ${ }^{35}$ Dass er der Insel Kuba ein vergleichbares Blutbad ersparen wollte und politisch für einen Weg über Reformen plädierte, steht ebenso außer Frage.

Der preußische Schriftsteller und Gelehrte, der sich zum Zeitpunkt der Haitianischen Revolution zweimal zu mehrmonatigen Aufenthalten auf der Nachbarinsel Kuba befand, hatte sich freilich schon früh aus der Perspektive der in Paris proklamierten Menschenrechte mit der aus seiner wissenschaftlich fundierten Sicht verabscheuenswürdigen und durch nichts zu rechtfertigenden Sklavenwirtschaft auseinandergesetzt. Bezüglich des Umgangs mit Sklaven notierte er am 6. Dezember 1800 an Bord eines Schiffes auf dem Weg nach Kuba: „Man kann nichts übertreiben, so schändlich ist diese Behandlung. “36 In Europa spreche

33 Vgl. Humboldt, Alexander von: Relation historique du Voyage aux Régions équinoxiales du Nouveau Continent ... Nachdruck des 1814-1825 in Paris erschienenen vollständigen Originals, besorgt, eingeleitet und um ein Register vermehrt von Hanno Beck. 3 Bde. Stuttgart: Brockhaus 1970.

34 Vgl. hierzu die Angaben und zahlreichen Anmerkungen auch in der englischsprachigen Ausgabe dieses Grundlagenwerks in Humboldt, Alexander von: Political Essay on the Island of Cuba. A Critical Edition. Edited with an Introduction by Vera M. Kutzinski and Ottmar Ette. Translated by J. Bradford Anderson, Vera M. Kutzinski, and Anja Becker. With Annotations by Tobias Kraft, Anja Becker, and Giorleny D. Altamirano Rayo. Chicago - London: The University of Chicago Press 2011. Entsprechende Passagen sind leicht über das Register auffindbar.

35 Vgl. hierzu ausführlich Ette, Ottmar: Insel-Text und archipelisches Schreiben: Alexander von Humboldts „Isle de Cube, Antilles en général“. In: edition humboldt digital. Hg. von Ottmar Ette. Berlin: Berlin-Brandenburgische Akademie der Wissenschaften. Version 1 vom 10.5.2017. <URL: http://edition-humboldt.de/v1/H0016213>; in gedruckter Form auch in Insel-Text und archipelisches Schreiben: Alexander von Humboldts „Isle de Cube, Antilles en général“. In: Jaglarz, Monika / Jástal, Katarzyna (Hg.): Bestände der ehemaligen Preußischen Staatsbibliothek zu Berlin in der Jagiellonen-Bibliothek. Forschungsstand und -perspektiven. Berlin: Peter Lang 2018, S. 205220.

36 Humboldt, Alexander von: Lateinamerika am Vorabend der Unabhängigkeitsrevolution. eine Anthologie von Impressionen und Urteilen aus seinen Reisetagebüchern. Mit einer einleitenden Studie von Manfred Kossok. 2., durchgesehene und verbesserte Auflage. Berlin: Akademie Verlag 2003, S. 247. Ich danke Tobias Kraft für den Hinweis auf diese Passage. 
man zwar bewundernd vom Glanz von Saint-Domingue, doch alles Unnatürliche müsse früher oder später verschwinden: „Und es ist nicht natürlich, dass ein paar Felseninseln so viel hervorbringen. “37 Humboldt war sich der Tatsache bewusst, dass die Erwirtschaftung so großer Reichtümer nur durch eine bis an ihre äußersten Grenzen getriebene Ausbeutung von Sklaven möglich sein konnte - und ein derartiges Profitsystem verabscheute er zutiefst.

In seinem Politischen Versuch über die Insel Kuba führte er wiederholt anhand konkreten Zahlenmaterials vor, in welchem Maße Saint-Domingue das System der Plantagenwirtschaft auf die Spitze getrieben hatte. Und hatte der Zusammenbruch der französischen Kolonie nicht auch die verstärkte Einfuhr schwarzer Sklaven nach Kuba ausgelöst? Humboldt belegte dies anhand der offiziellen Einfuhrzahlen des Hafens von Havanna, wobei er in seiner Erfassung der Jahre 1790 bis 1820 zwei große Sprünge nachwies. So stiegen die Zahlen eingeführter Sklaven zwischen 1801 und 1802 von 1659 auf 13832 sowie zwischen 1814 und 1816 von 4321 über 9111 auf 17737, um im darauffolgenden Jahr 1817 den Spitzenwert von 25841 Sklaven zu erreichen, die allein über den Hafen von Havanna aus Afrika deportiert worden waren. ${ }^{38}$ Und dies waren nur die offiziellen Zahlen, die sich Humboldt zugänglich gemacht hatte.

Was Sklaverei und Plantagenwirtschaft für das Zusammenleben der Menschen in abhängigen Kolonialsystemen bedeuteten, hatte Humboldt selbst seit seinem Aufenthalt im heute venezolanischen Cumaná 1799 immer wieder im weiteren Verlauf seiner Reise hautnah miterlebt. Auf der Überfahrt von Guyaquil nach Acapulco etwa musste er entsetzt zur Kenntnis nehmen, dass ein Mitreisender, ein gut angezogener junger Mann, an Bord des Schiffes eine seiner Sklavinnen mit einem Messer ermordet hatte. Humboldt formulierte in seinem Tagebucheintrag vom 4. März 1803 nicht allein seine tiefe Abscheu, sondern stellte diese Szenerie in den Kontext aktueller politischer Entwicklungen, mit denen das napoleonische Frankreich - durch die blutigen Aufstände gegen die Tyrannei der Sklavenwirtschaft keines Besseren belehrt - mit der Wiedereinführung der Sklaverei die Kolonien und insbesondere Saint-Domingue wieder unter seine Kontrolle bringen wolle:

Diese Nachricht erfüllte uns umso mehr mit Schrecken, als uns wenige Tage vor unserer Einschiffung die Gazette mit der grässlichen Rede von Bruix zugegangen war, in welcher er als Redner der Regierung der legislativen Körperschaft vorschlug, die Sklaverei wieder einzuführen und den Sklavenhandel auf dieselbe Weise durchzuführen, wie er vor 1789 bestanden hatte. Wir waren glücklicherweise in einer Gesellschaft, in welcher viele Menschen den

37 Ebda., S. 248.

38 Humboldt, Alexander von: Relation historique, Bd. III, S. 404. 
moralischen Schrecken teilten, mit der man eine so bestürzende Nachricht aufnehmen muss. Dies also ist die Frucht von so viel Blut, das auf den Antillen vergossen wurde [...]. ${ }^{39}$

Früh schon setzte sich Humboldt mit den ökonomischen, politischen, juristischen und sozialen Folgen auseinander, welche die blutigen Entwicklungen von SaintDomingue für das weltweit ausgespannte Netzwerk der Plantagenwirtschaft zeitigen mussten. Es ist keineswegs so, dass er die Revolution der Sklaven auf Haiti in seinen Schriften ignoriert hätte, wie bisweilen zu lesen war. Denn er entwickelte in seinen Betrachtungen rasch eine Position, welche einerseits von Verständnis für die Revolution der Sklaven gegen ihre Herren geprägt war und andererseits das Ziel verfolgte, eine derartige blutige Revolution in anderen Teilen des Kolonialreichs zu verhindern. Humboldt verurteilte die Exzesse und Massaker, so wie er auch der „Terreur“ während der Französischen Revolution ablehnend gegenüberstand. Doch hatte er die historische Bedeutung beider Revolutionen, der Französischen wie der Haitianischen, im Grunde sehr wohl verstanden.

Alexander von Humboldt war selbstverständlich nicht nur mit Blick auf die französischen Kolonien vehement gegen die Sklaverei: Er bekämpfte sie auf seine diplomatische, aber stets beharrliche und entschiedene Weise auch andernorts und gerade auch dort, wo eine Revolution gegen das Kolonialsystem erfolgt war, ohne dass dieser Revolution eine Befreiung der Sklaven gefolgt wäre. So kritisierte er in einem Brief vom 20. Juni 1804 aus Philadelphia an William Thornton die Sklaverei-Gesetzgebung in den Südstaaten der USA in scharfem Ton und verband seine Kritik mit der dezidierten Frage nach Gerechtigkeit sowie der Eindämmung eines rein ökonomischen Denkens. Ein kurzer Blick in diesen Brief ist aufschlussreich:

Je mehr die jüngsten Ereignisse von Saint-Domingue die Wahrheit verdunkelten, desto mehr erscheint es als Pflicht jedes moralischen Mannes, das Problem in seinem wahren Lichte darzustellen. [...] Es wäre schön, wenn die Südstaaten die Dinge vorbereiteten, ohne noch auf die gefährliche Krise des Jahres 1808 zu warten. Dieses verabscheuungswürdige Gesetz, welches die Einfuhr von Schwarzen ins südliche Carolina erlaubt, ist eine Schande für einen Staat, in welchem es meines Wissens sehr gut organisierte Köpfe gibt. Indem man alleine dem Laufe folgt, den die Menschlichkeit vorgibt, wird man wohl zu Beginn weniger Baumwolle ausführen. Aber ach!, wie verabscheue ich diese Politik, welche das öffentliche Glück einfach nach dem Werte der Ausfuhren bemisst und bewertet! [...] Bevor man frei ist, muss man gerecht sein, und ohne Gerechtigkeit gibt es keinen dauerhaften Wohlstand. ${ }^{40}$

39 Ebda., S. $249 \mathrm{f}$.

40 Humboldt, Alexander von: Briefe aus Amerika 1799-1804. Bearbeitet von Ulrike Moheit. Berlin: Akademie Verlag 1993, S. 300. 
In seinem Umgang mit den USA ging Alexander von Humboldt vielfach diplomatisch vor und vermied jegliche direkte Äußerung seiner Vorstellungen, die als Provokation hätte empfunden werden können. Doch bis an sein Lebensende vertrat er eine Position, welche gerade mit Blick auf die Vereinigten Staaten ein Ende der Sklaverei forderte und jeglicher Verfälschung seiner Überzeugungen einen Riegel vorschob. Als ein die Sklaverei befürwortender Übersetzer ins Englische seinen Politischen Versuch über die Insel Kuba gezielt so manipulierte, dass alle Aussagen Humboldts gegen die Sklaverei in Aussagen zugunsten der Sklaverei umgedeutet wurden, protestierte er ebenso heftig - und mit Hilfe von Anzeigen in der US-amerikanischen Massenpresse - wie letztlich erfolglos. Denn es wirft ein eigenartiges Licht auf die Philologie in den USA, wenn man konstatiert, dass nahezu alle US-amerikanischen Kollegen diese Übersetzung benutzten und für bare Münze nahmen. Gerade die „Postcolonial Critics“ griffen auf sie zurück, um Humboldt der Befürwortung von Sklaverei anzuklagen, bis wir schließlich von Potsdam und Nashville aus eine neue Übersetzung ins Englische vorlegten, ${ }^{41}$ welche diese Stimmen langsam verstummen ließ. Doch dies ist eine Geschichte, auf die ich in vielen Publikationen verwiesen habe - und es war kein Geringerer als der berühmte kubanische Anthropologe Fernando Ortiz, der wohl erstmals auf das Skandalon dieser Übersetzung aufmerksam machte. ${ }^{42}$

Lassen Sie uns unsere Digression zur klaren, bezüglich Heinrich von Kleist zeitgenössischen Auffassung Humboldts gegenüber der Sklaverei abschließen! Mit größerem zeitlichem Abstand warnte letzterer in seiner Analyse der Situation Kubas im karibischen Kontext vor einer Wiederholung des Endes der einst so reichen französischen Kolonie Saint-Domingue. Angesichts eines stetig steigenden Anteils schwarzer Sklaven an der Gesamtbevölkerung betonte er die immer wahrscheinlicher werdende Möglichkeit, dass ohne jedes Zutun der benachbarten haitianischen Republik auch auf anderen Antilleninseln eine neue revolutionäre Situation entstehen könnte, die zu einer zutiefst veränderten geopolitischen Lage führen müsse. Schauen wir uns diese Einschätzung also abschließend an:

41 Vgl. Humboldt, Alexander von: Political Essay on the Island of Cuba. A Critical Edition. Edited with an Introduction by Vera M. Kutzinski and Ottmar Ette. Translated by J. Bradford Anderson, Vera M. Kutzinski, and Anja Becker. With Annotations by Tobias Kraft, Anja Becker, and Giorleny D. Altamirano Rayo. Chicago - London: The University of Chicago Press 2011. Im Vorwort wird diese Geschichte kurz referiert.

42 Vgl. Ortiz, Fernando: El traductor de Humboldt en la historia de Cuba. In: Humboldt, Alejandro de: Ensayo Político sobre la Isla de Cuba. Nota preliminar por Jorge Quintana rodríguez. Introducción por Fernando Ortiz. La Habana: Publicaciones del Archivo Nacional de Cuba 1960, S. 359-385. 
Wenn die Rechtsprechung der Antillen und der Zustand der Bevölkerung der Farbigen nicht bald hilfreiche Veränderungen erfahren, wenn man weiterhin diskutiert, ohne zu handeln, dann wird das politische Übergewicht in die Hände derer fallen, die im Besitz der Arbeitskraft sind, des Willens, sich zu befreien, und des Mutes, lange Entbehrungen auszuhalten. Diese blutige Katastrophe wird sich als eine notwendige Folge der Umstände ereignen, und ohne dass sich die freien Schwarzen aus Haiti auch nur im Geringsten einmischen würden, ohne dass sie also das System der Isolierung aufgäben, das sie bislang befolgt haben. Wer würde es wagen, den Einfluss vorauszusagen, den eine zwischen Kolumbien, Nordamerika und Guatemala gelegene Afrikanische Konföderation der freien Staaten der Antillen auf die Politik der Neuen Welt ausüben würde? ${ }^{43}$

Indem er die Möglichkeit der Entstehung einer „Afrikanischen Konföderation“ im Zentrum der amerikanischen Hemisphäre ins Spiel brachte, skizzierte Alexander von Humboldt die radikale Offenheit einer Geschichte, die in ihrem Verlauf keinerlei vorgegebenem Muster mehr folgen würde. Denn längst hatten die ehemaligen Sklaven Haitis bewiesen, dass sie eine politische ,Agency' größten Ausmaßes entfalten konnten, eine Fähigkeit, die Humboldt fortan mit ins Kalkül zog. Gewiss kann man Humboldt aus heutiger Perspektive vorwerfen, von einer „Afrikanischen Konföderation“ gesprochen zu haben, wo doch die Bevölkerungen Haitis wie der Karibik allgemein gerade bei den Sklaven durch einen starken Transkulturationsprozess gegangen waren und keineswegs mehr als ,Afrikaner' angesprochen werden konnten. Doch mir scheint, dass derartige Vorwürfe das Eigentliche des Humboldt'schen Gedankens verhüllen oder zumindest am Wesentlichen vorbeigehen. Die „Historia“ hatte im Zeichen des Erlebens der Französischen Revolution aufgehört, im „Horizont neuzeitlich bewegter Geschichte“ noch als „Magistra Vitae“ zu dienen: ${ }^{44}$ Die Objekte europäischer Kolonialpolitik hatten angefangen, zu Subjekten ihrer eigenen Geschichte zu werden. Die Geschichte war als Globalgeschichte wie als Regionalgeschichte nicht mehr vorhersagbar und den Zeitgenossen begann zu dämmern, dass in dieser neuen zeitgeschichtlichen Konstellation alles möglich war und alles vom Menschen und seinem Tun abhing.

Damit war die Frage nach der Zukunft und vor allem nach den Möglichkeiten und Grenzen eines Zusammenlebens innerhalb einer grundlegend veränderten Machtkonstellation in der Neuen Welt gestellt: innerhalb einer neuen Verteilung von Gewalt und Einfluss, in der die ehemaligen Sklaven - dem Beispiel der Schwarzen in Saint-Domingue folgend - zu Herren ihrer eigenen Geschichte,

43 Humboldt, Alexander von: Relation historique, Bd. III. Stuttgart: Brockhaus 1970, S. 389. 44 Vgl. hierzu Koselleck, Reinhart: Historia Magistra Vitae. Über die Auflösung des Topos im Horizont neuzeitlich bewegter Geschichte. In (ders.): Vergangene Zukunft. Zur Semantik geschichtlicher Zeiten. Frankfurt am Main: Suhrkamp 21984, S. 38-66. 
ihres eigenen Schicksals werden konnten. Am Beginn des 19. Jahrhunderts schien die Geschichte wieder völlig offen. Und wir tun gut daran, uns diese Offenheit des damals historisch Entstehbaren immer wieder vor Augen zu halten. Es war in keiner Weise absehbar, dass das 19. Jahrhundert das Jahrhundert eines ins Absurde gesteigerten europäischen Kolonialismus werden würde und dass sich die Rivalitäten der europäischen Mächte auf die Verteilung von Ländern auf ganzen Kontinenten richten würden. Wie aber würden sich dann zu einem Zeitpunkt, zu dem in vielen Regionen des zirkumkaribischen Raumes - einschließlich der Südstaaten der USA - die Sklaverei auch weiterhin herrschte, die Grundlagen und ,Spielregeln“ des Zusammenlebens verändern? Welche Möglichkeiten künftiger Konvivenz konnten nicht nur imaginierbar und denkbar, sondern auch schreibbar und gesellschaftlich lebbar werden?

Selbst also für den Fall, dass sich Saint-Domingue - entgegen der von den Kolonialherren und Zuckerrohrpflanzern überall in der Karibik geäußerten Befürchtungen - als letztlich nur kleine politische Macht nicht in die Angelegenheiten der europäischen Kolonialmächte ${ }^{45}$ oder der USA einmischen würde, war nun eine Frage auf radikale Weise gestellt: Wie sollte ein künftiges Zusammenleben ebenso im nationalen und regionalen wie im hemisphärischen und transarealen Maßstab zu gestalten und zu organisieren sein? Innerhalb dieses transareal diskursiven Feldes situiert sich auch die hier untersuchte Erzählung des Heinrich von Kleist.

Denn man darf ohne jede Übertreibung behaupten, dass der in Preußen aufgewachsene Schriftsteller durch Die Verlobung in St. Domingo wie mit einem literarischen Brennspiegel auf all jene Herausforderungen reagiert und komplexe Antworten zu geben versucht, welche Alexander von Humboldts Reaktionen auf die Haitianische Revolution geradezu exemplarisch vor Augen führen. Damit ist keine wie auch immer geartete, realistische‘ Mimesis, keine dargestellte Wirklichkeit im traditionellen Sinne gemeint. Vielmehr wird eine verdichtete Darstellung gelebter und lebbarer Wirklichkeit, das historisch Vorgefundene mit dem literarisch Erfundenen so zu einem Erprobungsraum konfiguriert, dass das Lebbare und Erlebbare wie in einer Laborsituation in diesem ersten Dreieck nicht allein imaginiert, sondern zugleich erkundet und mehr noch durchgespielt, ja vom Lesepublikum durcherlebt werden kann. Die Verlobung in St. Domingo bildet, so scheint mir, in geradezu idealtypischer Weise einen derartigen experimentellen Erprobungsraum - und zwar keineswegs zufällig am Beispiel jenes Haiti, das im

45 Aus einer eingestandenermaßen sehr spezifischen Perspektivik wird Kleists Erzählung analysiert in Zantop, Susanne: Colonial Fantasies. Conquest, Family, and Nation in Precolonial Germany, 1770-1870. Durham - London: Duke University Press 1997, S. 155. 
globalen Maßstab als Herausforderung und Paradigma zugleich die Frage nach Konvivenz im weltweiten Maßstab radikal stellte. Heinrich von Kleist hatte also ein literarisches Sujet gewählt, das es ihm jenseits der Enge Preußens erlaubte, die ganz großen Fragen an die Menschheitsgeschichte zu stellen: Gerade darin war er Preuße. ${ }^{46}$

Eben weil Kleists Erzählung von Beginn an auch stereotype Darstellungen von einem Kampf der Rassen in Saint-Domingue in die literarische Modellierung aufnimmt, wird es möglich, diese Erzählung als einen Erprobungsraum für die Chancen und Risiken künftigen Zusammenlebens zu begreifen. Es handelt sich dabei um ein Zusammenleben nicht nur auf Hispaniola oder in der Karibik, sondern im Kontext der zweiten Phase beschleunigter Globalisierung in der ganzen Neuen wie der Alten Welt. Dies wird in der Erzählung auch deutlich markiert. Die Verlobung in St. Domingo avancierte damit zu einem höchst vieldeutigen und vielstimmigen Text, der auf die Herausforderungen einer durch die Haitianische Revolution zutiefst erschütterten Praxis der Globalisierung reagierte und komplexe Sinnangebote entwickelte, welche für die zeitgenössische Leserschaft herausfordernd waren.

Diese Sinnangebote stellen sich der Frage, wie zu Beginn einer neuen historischen Epoche, an deren Horizont sich nicht nur der Untergang einer auf Sklaverei gegründeten Plantagenwirtschaft, sondern des gesamten Kolonialsystems europäischer Prägung abzeichnet, neue Lebensformen und Lebensnormen entwickelt werden können, die ein künftig friedliches Zusammenleben zu regeln in der Lage wären. Damit rücken Aspekte einer zukünftigen Weltgesellschaft in den Fokus, aus welcher der europäische und auch alle anderen Kolonialismen ein für alle Mal verbannt wären und die entscheidenden Fragen nach Konvivenz in Frieden und in Differenz gestellt werden würden. Wie aber ließe sich Die Verlobung in St. Domingo über die Behandlung des historischen Paradigmas hinaus in einem prospektiven Sinne als Erprobungsraum künftigen Zusammenlebens verstehen und lesen? Gibt es Bedeutungsebenen im Text, die auf eine allgemeine Konvivenz im Weltmaßstab abzielen?

Fragen wir angesichts dieser dringlichen Themen nach den Entstehungsbedingungen des Textes! In der Kleist-Forschung ist es unstrittig, dass Heinrich von Kleist entscheidende Anregungen zu diesem Stoff durch seine Aufenthalte in den Jahren 1801/1802 sowie 1803 in Paris, 1802 in der Schweiz sowie vor allem durch seine Inhaftierung als französischer Kriegsgefangener im Jahr 1807 in der im Jura unweit der Schweizer Grenze imposant gelegenen Festung Joux erhalten

46 Vgl. Ette, Ottmar: Mobile Preußen. Ansichten jenseits des Nationalen. Stuttgart: J.B. Metzler Verlag 2019. 
haben dürfte. ${ }^{47}$ Ein gut sichtbarer Gedenkstein erinnert an diesem Ort noch immer an die Tatsache, dass in der Forteresse de Joux in einer engen, kalten Zelle der einst so mächtige „Sklavengeneral“ und „schwarze Spartakus“ François Dominique Toussaint-L'Ouverture (1745-1803) jämmerlich zugrunde ging. Er war am 15. Juni 1802 an die napoleonischen Truppen verraten und unter unmenschlichen Bedingungen nach Frankreich verbracht worden - in eben jene Todeszelle, in welcher sich Kleists Bekannter Gauvain vier Jahre später in Haft befand. ${ }^{48}$ Gerade die letztgenannte ,Begegnung ' mit der Geschichte der Haitianischen Revolution muss den Frankfurter Dichter stark beeindruckt haben.

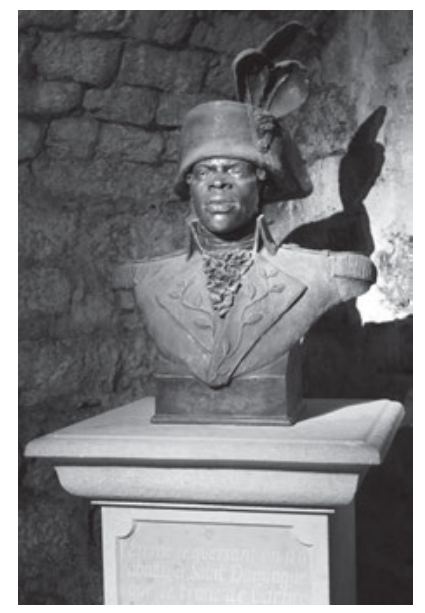

Abb. 15: Büste von Toussaint-L'Ouverture (1745-1803) im Fort de Joux.

Nicht nur durch die französische und deutsche Presse, durch die in die Schlussphase der Haitianischen Revolution fallenden Aufenthalte in Paris sowie durch seinen über die Vorgänge in Saint-Domingue gut informierten Freund Zschokke dürfte Kleist mit für ihn wichtigen Materialien versorgt worden sein. Auch durch die geradezu hautnahe Berührung gewann jene Welt von Toussaint-L'Ouverture, ${ }^{49}$ die Kleist so fern sein musste, eine dennoch gewaltige Faszinationskraft. Die persönliche Beziehung über die Forteresse de Joux dürfte als eine Art Auslöser fun-

47 Vgl. Loster-Schneider, Gudrun: Toni, Babekan und Homi Bhabha? Zu Problemen kultureller und ästhetischer Hybridisierung in Heinrich von Kleists „Die Verlobung in St. Domingo“, S. 228. 48 Ebda., S. 230. Vergleiche hierzu auch Kleist, Heinrich von: Sämtliche Werke in vier Bänden, Bd. IV, S. 374.

49 Vgl. hierzu auch Bernecker, Walther L.: Kleine Geschichte Haitis, bes. S. 41. Eine kurze biographische Skizze des als Sklave geborenen Revolutionsgenerals findet sich auch in Buch, Hans Christoph: Die Scheidung von San Domingo, S. $173 \mathrm{f}$. 
giert haben, aber die Grundfragen, die Kleist an dieses Sujet stellte, entwickelten sich innerhalb eines wesentlich weiter gesponnenen Horizonts.

Aber war diese Welt, war gerade auch diese karibische Welt wirklich so fern? Hatte die neue globale Ordnung, die Napoleon für eine Welt unter französischer Vorherrschaft ersann, nicht den haitianischen Sklavengeneral Toussaint-L'Ouverture ebenso wie den aus einem alten Geschlecht preußischer Generäle stammenden Kleist gleichermaßen in die Forteresse de Joux gespült? Hingen die Besetzung des aufständischen Haiti und die Besetzung Berlins durch französische Truppen nicht unmittelbar miteinander zusammen? Und stand Preußen nicht im Begriff, zu einer bloßen innereuropäischen Kolonie, zu einer Marionette im globalen Machtspiel Frankreichs zu verkommen?

Manche Züge der Figur des blutrünstigen Congo Hoango mögen an Charaktermerkmale erinnern, die Toussaint-L'Ouverture und - gerade mit Blick auf eine „unmenschliche Rachsucht“50 - mehr noch Dessalines im kolonialistischen Diskurs nachgesagt wurden. Der Vorhang der Kleist'schen Erzählung jedenfalls hebt sich mit Bedacht erst während der Abwesenheit von Congo Hoango, der wie wir sahen - kein gewöhnlicher Schwarzer und Sklave ist, sondern über eine gewisse Macht und Befehlsgewalt verfügt. Als Vertreter der sich herausbildenden neuen Herrschaftsstrukturen ist er ein schwarzer Herr, der anders als seine Gefolgsleute, die im Stall wohnen, mit der alten Babekan und deren Tochter, „einer jungen fünfzehnjährigen Mestize“ namens Toni, „das Hauptgebäude der Pflanzung“"51 bewohnen kann. Dieses einsam an einer Landstraße liegende Gebäude wird zum eigentlichen Schauplatz einer Geschichte, deren Fäden sich in diesem Haus kreuzen und verknoten. Denn das Haus, irgendwo zwischen Fort Dauphin und Port-au-Prince gelegen, wird zum ebenso heimlichen wie unheimlichen zentralen Protagonisten der Erzählung. Es gerät zu einem wirklichen Haus in der Karibik, ${ }^{52}$ das nicht nur Schauplatz einer Geschichte ist, sondern selbst in die Handlung eingreift und die Komplexität einer absurden, aber realen Geschichte verkörpert.

Dieses Haus also, das bis vor kurzem noch dem Sklavenhalter Guillaume von Villeneuve gehört hatte, erscheint zunächst als Falle, versuchen Congo Hoango und Babekan doch erfolgreich, auf Hilfe angewiesene Weiße mit tatkräftiger Unterstützung der schönen Toni ins Haus zu locken, „die, wegen ihrer ins gelb-

50 Kleist, Heinrich von: Die Verlobung in St. Domingo, S. 9.

51 Ebda.

52 Vgl. hierzu das vierte Kapitel „Karibische Inselwelten“ in Ette, Ottmar: ZwischenWeltenSchreiben. Literaturen ohne festen Wohnsitz (ÜberLebenswissen II). Berlin: Kulturverlag Kadmos 2005, S. 123-155. 
liche gehenden Gesichtsfarbe, zu dieser gräßlichen List besonders brauchbar war“".53 Ein zweites Dreieck tut sich auf: zwischen einer mörderischen List, die es erlaubt, eine durch Sklaverei und Kolonialismus ererbte Last, die aus immer wieder benannten und bis vor kurzem erlittenen Demütigungen und Misshandlungen besteht, in eine Lust umzuwandeln, die als Mordlust zweifellos im Zeichen der Rache an den Weißen und ihrem grausamen System der Unterdrückung und hemmungslosen Ausbeutung steht.

Kleists Erzählung präsentiert uns diese Lust von Congo Hoango wie von Babekan freilich von Beginn an als verwerflich, wird sie an der Textoberfläche doch ins Zeichen einer Undankbarkeit gestellt, die den Mörder des wohltätigen Herren in einen Herren über grausame Mörder verwandelte. Die hellhäutige Toni nimmt dies billigend in Kauf und hat neben mehreren Franzosen auch schon Portugiesen oder Holländer in die tödliche Falle des Hauses gelockt. Sie selbst ist dabei sozusagen der Lockvogel, der mit seiner Hautfarbe, aber auch mit seinen weiblichen Reizen die überwiegend männlichen Europäer in Sicherheit zu wiegen vermag.

In der Kleist'schen Erzählung stehen sich folglich nicht nur Schwarze und Weiße gegenüber. Zwischen weiß und schwarz befinden sich die Mulattin Babekan und ihre Tochter Toni, die - wie ihre gelbliche Gesichtsfarbe es in der Erzählung anzeigt - ebenfalls Mulattin ist. Der Text bezeichnet sie begrifflich unzutreffend als „Mestize“, ist Toni doch keineswegs aus einer Verbindung zwischen indigener (indianischer) Bevölkerung und weißen Kolonisatoren oder Zuwanderern hervorgegangen. Auf struktureller Ebene ist diese Bezeichnung jedoch aufschlussreich nicht nur, weil Heinrich von Kleist einer zeitgenössischen Wendung auf den französischen Antillen gefolgt sein dürfte, bei der die Benennung als „métisse“ gleichsam den ,schwarzen', afrikanischen Anteil auszublenden pflegt, um die entsprechende Person hinsichtlich ihrer weißen Herkunft aufzuwerten. ${ }^{54}$ Denn das von Kleist für Toni offenkundig sehr bewusst gewählte Lexem „Mestize“ integriert zusätzliche Sinnebenen, blendet die junge Frau in ihrer schillernden Gestalt, in ihrem fundamentalen ,Dazwischen-Sein` auf diese Weise doch die schon von den Spaniern größtenteils ausgerottete indigene Bevölkerung ein, so dass die schöne Toni sich auf der begrifflichen Ebene im dritten Dreieck zwischen

53 Kleist, Heinrich von: Die Verlobung in St. Domingo, S. 10.

54 In verschiedensten Zusammenhängen wird diese begriffliche Verwendung beleuchtet von dem weitgereisten Schriftsteller irisch-griechischer Abstammung Lafcadio Hearn; vgl. hierzu seinen gegenüber den japanischen Schriften weniger beachteten originellen Reisebericht Two Years in the French West Indies, wiederabgedruckt in Hearn, Lafcadio: American Writings. New York: The Library of America 2009, S. 149-541. 
Europa, Afrika und Amerika bewegt. Die „Mestize“ ist auf den verschiedensten Ebenen eine Bewegungs-Figur - und genau dies ist es, was Kleist an ihr herausarbeiten wollte.

Die vom Erzähler ostentativ gewählte scheinbar ,fehlerhafte‘, ,unzutreffende‘ Terminologie verwandelt Toni in ein Wesen, das als eigentliche Bewegungsfigur mehr als jeder andere Mensch in Kleists Erzählung für die Karibik in der ersten wie in der zweiten Phase beschleunigter Globalisierung einzustehen vermag. Dass ihr Vater ein reicher französischer Kaufmann aus Marseille ist, ${ }^{55}$ der später als Gesandter der jungen Französischen Republik an den türkischen Hof nach Istanbul gegangen sei, ${ }^{56}$ verstärkt diesen Aspekt: Toni ist ein Produkt all jener Bewegungen, in denen von Europa aus Ostindien und Westindien, Asien, Amerika und Afrika globalisiert und in abhängige Kolonialgebiete verwandelt wurden.

Gewiss lässt sich die Farbe Gelb im Farbenspektrum zwischen schwarz und weiß verorten, wie dies in der Forschung immer wieder herausgearbeitet wurde. ${ }^{57}$ Gelb schreibt sich darüber hinaus jedoch in eine lange patriarchalisch-kolonialistische und sexistische Tradition in der Karibik ein. In dieser ist aus der Perspektive des weißen Mannes - und hier öffnet sich ein weiteres, viertes Dreieck, das diesmal abhängige Geschlechterbeziehungen betrifft - die schwarze Frau vor allem für die Arbeit, die weiße Frau vorrangig für die Ehe und die Mulattin für Lust und Liebe vorgesehen. ${ }^{58}$ Es ist die sexistisch-kolonialistische Figur heterosexueller Konvivenz par excellence, die ihren Rassismus offen zur Schau trägt.

Kein Wunder also, wenn die schöne Mulattin nicht nur zum Mythos, sondern bald auch zum Gegenstand literarischer Allegoresen wurde, die sich auf die emergierenden Nationen der amerikanischen Hemisphäre bezogen. Denn in dieser Figur floss alles zusammen. Im weiteren Verlauf des 19. Jahrhunderts avancierte im spanischsprachigen Raum - und die Nachbarinsel Kuba bietet hier das sicherlich beste Beispiel - die „mulata“ zur Verkörperung der künftigen Nation, bot ihre Allegorese doch im Kontext problematischer Nationenbildungsprozesse die Möglichkeit, bei hohem identifikatorischem Wert die Schönheit wie das Scheitern dieses Projekts angestrebter Konvivenz ebenso sinnlich wie hautnah vorzufüh-

55 Kleist, Heinrich von: Die Verlobung in St. Domingo, S. 27.

56 Ebda., S. 28.

57 Vgl. etwa Uerlings, Herbert: Poetiken der Interkulturalität. Haiti bei Kleist, Seghers, Müller, Buch und Fichte. Tübingen: Max Niemeyer 1997, S. 25-40.

58 Vgl. hierzu u.a. Phaf, Ineke: Motivforschung altmodisch? Mit der Mulattin zu einem karibischen Nationaltext. In: Kohut, Karl (Hg.): Rasse, Klasse und Kultur in der Karibik. Akten der Fachtagung „Rassenbeziehungen und Rassenbegegnungen in der Karibik“ am 15. und 16. Mai 1987 an der Katholischen Universität Eichstätt. Frankfurt am Main: Vervuert 1989, S. 85-98. 
ren. ${ }^{59}$ So spielte die Mulattin als Identifikationsfigur und Allegorese im 19. Jahrhundert eine zentrale Rolle in der Gesellschaft und mehr noch in der Literatur. Kleist greift motiv- und stoffgeschichtlich gleich zu Beginn dieses Jahrhunderts erstaunlich früh auf diese Zentralfigur zurück.

In der französischsprachigen Karibik hatte sich die Farbe Gelb weit stärker und weit früher als im spanischsprachigen Raum als Euphemismus für alles ,Mulattische' durchgesetzt. So findet sich diese rassistisch eingefärbte ,Farbenlehre“ in einschlägigen Texten wie etwa bei Moreau de Saint-Méry, der neben Weiß und Schwarz das Gelbe als eine dritte Schattierung bezeichnet: „La troisième nuance est celle du Mulâtre qu'on pourrait presque subdiviser en deux, attendu que les Mulâtres comparés entr'eux, offrent deux nuances très distinctes qui sont exactement celle du cuivre rouge \& celle du cuivre jaune. "60 Médéric-Louis-Elie Moreau de Saint-Méry hatte in seinem Werk von 1802 über Saint-Domingue, das zu einer wichtigen Quelle Heinrich von Kleists wurde, ${ }^{61}$ höchst komplizierte farbliche Unterteilungen ins Feld geführt, wie sie sich im Übrigen zeitgenössisch auch in anderen Teilen der Karibik finden lassen. Kleist konzentrierte sich im Farbenspektrum jedoch auf das Gelbe, wie wir es bereits im Incipit am Namen des Congo Huango feststellen konnten.

Wie etabliert die Begrifflichkeit der Farbe Gelb als Bezeichnung für eine Situierung unter den „mulâtres“ im frankophonen Raum der Karibik war, mag auch der nachfolgende Beleg aufzeigen:

Die Begründung dieser rassischen Nomenklatur bestand darin, auf möglichst „wissenschaftliche“ Weise vorgeblich zu unterstreichen, dass das Fehlen von schwarzem Blut auf immer unauslöschbar war. So werden die Freien von den Weißen bisweilen „MischBlut“, bisweilen „People of Colour“, bisweilen „Mulatten“ genannt, später werden sie von den Schwarzen aus Saint-Domingue als „Gelbe“ bezeichnet. Was die Benennungen als „Mestize“ oder als „métive“ angeht, so werden sie für die sehr seltenen Nachfahren von Indianern reserviert. Auf den Inseln über dem Winde kümmert man sich nicht um solche Subtilitäten: Die Freien heißen im Allgemeinen „Mulatten“. ${ }^{62}$

59 Vgl. hierzu Ette, Ottmar. Cirilo Villaverde: „Cecilia Valdés o La Loma del Angel“. In: Roloff, Volker / Wentzlaff-Eggebert, Harald (Hg.): Der hispanoamerikanische Roman. Band 1: Von den Anfängen bis Carpentier. Darmstadt: Wissenschaftliche Buchgesellschaft 1992, S. 30-43.

60 Moreau de Saint-Méry, Louis Elie: Description topographique, physique, civile, politique et historique de la partie française de l'île de Saint-Domingue. 2 Bde. Philadelphie 1797, S. 75. Mit dem Titel dieses wichtigen Werkes dürfte Kleist bei seiner Titelgebung gespielt haben. Ich danke Gesine Müller für den Hinweis auf diese Verbindung.

61 Vgl. hierzu Loster-Schneider, Gudrun: Toni, Babekan und Homi Bhabha? Zu Problemen kultureller und ästhetischer Hybridisierung in Heinrich von Kleists „Die Verlobung in St. Domingo“, S. 229 und 238.

62 Abénon, Lucien-René: La Révolution aux Caraïbes. Antilles 1789. Paris: Nathan 1989, S. 61. 
Sie haben es bemerkt: Ich habe absichtlich den französischen Ausdruck „gens de couleur“ durch den englischsprachigen Ausdruck „People of Colour“ ersetzt, um klarzumachen, dass es sich dabei um einen durch und durch rassistischen Begriff handelt. In den letzten Jahren ist man ja auf diesen ausgewichen und benennt diejenigen, die man im Deutschen an diese Terminologie angelehnt rassistisch als „Farbige“ bezeichnete, mit dem englischen Vernebelungsbegriff als „People of Colour“ oder „Free People of Colour“. Auch das „libre“, das Freie, fehlt in der obigen Analyse des rassistischen Grundvokabulars der europäischen Kolonisatoren nicht und macht den Begriff beileibe nicht besser. Ich glaube nicht, dass es eine gute Idee ist, auf einen englischen Begriff überzuwechseln, welcher Teil eines bis heute in den USA durch und durch rassistischen Vokabulars ist, in einem Land, dessen Einwanderungsbehörden sich noch immer rassistischer Bezeichnungen bedienen und wo der Begriff „weiß“ eine spezifisch kulturelle Konnotation besitzt. ${ }^{63}$ Ich finde, dies sollten Sie wissen, wenn Sie den Begriff „Free People of Colour“ in den Mund nehmen.

Doch nochmals zurück zu unserem Zitat! Denn deutlicher könnte darin ganz nebenbei die terminologische Grenze zwischen ,Mestize“ und ,Mulatte“ nicht gezogen sein. Dass diese biologistische, primär auf die Hautfarbe bezogene Unterscheidung im 19. Jahrhundert kulturalisiert und etwa auf die in Entstehung begriffene haitianische Literatur übertragen werden konnte, zeigt die Kategorie der „littérature jaune“, der unter diesem Titel eine in zwei Teilen veröffentlichte Studie in der renommierten Pariser Revue des deux Mondes gewidmet werden konnte. ${ }^{64}$ Gustave d'Alaux versuchte in diesem aufschlussreichen Artikel, der haitianischen Literatur Existenzrecht zu verschaffen und erstmals aus literarhistorischer Sicht gerecht zu werden, wobei er allerdings die „Gelbe Literatur“ ins Zeichen des Plagiats und der Imitation fremder, europäischer Modelle französischer Provenienz rückte. Sie sehen, wie intim der Rassismus mit kulturellen Zuschreibungen verquickt ist! Zugleich aber machte der Verfasser damit die Existenz dieser im eigentlichen Sinne als haitianisch zu bezeichnenden „littérature jaune“ ein für alle Mal in Europa aktenkundig. Auch ein solcher Artikel in der Revue des deux Mondes gehört zu einer literarhistorischen Darstellung des 19. Jahrhunderts zwischen zwei Welten dazu.

63 Vgl. zur spezifischen Situation in den USA Painter, Nell Irving: A History of White People. New York - London: W.W. Norton 2009.

64 Vgl. hierzu ausführlich Müller, Gesine: Die koloniale Karibik. Transferprozesse in hispanophonen und frankophonen Literaturen. Berlin - Boston: Walter de Gruyter 2012, darin besonders das Unterkapitel IV.4.1.1. Die „littérature jaune“ zwischen Frankophilie und Plagiat. 
Es kann kein Zweifel daran bestehen, dass Heinrich von Kleist auch über Moreau de Saint-Méry hinaus mit Teilen dieser sich spätestens im 18. Jahrhundert im französischsprachigen Bereich verbreitenden Begriffsverwendung gut vertraut war. Und so verweist in seiner Erzählung Die Verlobung in St. Domingo die gelbe Gesichtsfarbe auch nicht nur auf eine mulattische Herkunft, sondern impliziert auch kulturelle Werte und Dispositionen, die - wie der weitere Verlauf der Erzählung zeigt - vom männlichen Protagonisten Gustav beziehungsweise August gleichsam an der Haut und an den Augen, an der Körperoberfläche der schönen jungen Frau abgelesen werden können - oder zumindest abgelesen werden sollen. Rassismus besteht in seinem Urgrund immer auf der systematischen Übertragung von Merkmalen der Natur - also der physischen Beschaffenheit des Körper-Leibes - auf den Bereich der Kultur, auf das Vermögen oder Unvermögen von Menschen, sich kultureller Praktiken zu bedienen. Wir werden noch verschiedentlich Beispiele hierfür auf unserem Weg durch das 19. Jahrhundert finden.

Die Farbe Gelb, die wir auf indirekte Weise schon im Namen von Congo Hoango aufleuchten sahen, wird im Verlauf der Erzählung immer wieder neu kontextualisiert. So etwa unmittelbar nach ihrem ersten expliziten Auftauchen durch den Hinweis auf das Vorrücken von „General Dessalines mit 30,000 Negern“65 auf Port au Prince, wo sich nun „Alles, was die weiße Farbe trug“66 gesammelt habe, um nicht vollends ausgelöscht zu werden. Dies ist die in Die Verlobung in St. Domingo mit wenigen Strichen kurz und prägnant skizzierte Situation in der Schlussphase der Haitianischen Revolution, als das eigentliche Geschehen, von dem Kleists Erzählung berichtet, mit dem nächtlichen Klopfen eines Fremden an „die hintere Thür“ des ehemaligen Herrenhauses von Guillaume von Villeneuve einsetzt. ${ }^{67}$ Auf Babekans Frage zu Beginn dieses ,Nachtstücks“, „wer da sei?“, ${ }^{68}$ antwortet der Fremde unter Anrufung von „Maria und allen Heiligen“69 - also ,Toussaint ${ }^{70}$ - mit einer Gegenfrage: „seid ihr eine Negerin?“71 Mit einer klugen Verrätselung ihrer Antwort öffnet die Mulattin das Tor; und mit dieser ,Ouverture‘, die gleichsam den Namen des berühmten Gefangenen von der Festung von Joux in den Text einschreibt, beginnt der Handlungskern des Kleist'schen Revolutionsstücks. Heinrich von Kleist ist ein Meister der Verdichtung bestimmter historischer

65 Kleist, Heinrich von: Die Verlobung in St. Domingo, S. 10.

66 Ebda., S. 11.

67 Ebda.

68 Ebda.

69 Ebda.

70 Die Anrufung wiederholt sich in Gustavs Formel „Gott und alle Heiligen“, die sich nur wenige Seiten später findet (Ebda., S. 17).

71 Ebda., S. 12. 
Fragmente und Reminiszenzen in der literarischen Schöpfung und Ausgestaltung seiner Texte: Seine Arbeit ist ästhetische Verdichtungsleistung.

Dazu gleich noch weitere Beispiele! Denn wie meisterhaft es Kleist verstand, makrohistorische Entwicklungen in mikrohistorische und vor allem mikronarrative Bewegungen zu übersetzen, zeigt Die Verlobung in St. Domingo auf beispielhafte Weise. Dass der fremde Weiße in stockfinsterer schwarzer Nacht mit der Hand nach Babekan greift, um leibhaftig und haptisch zu begreifen, hat mit der ihn bis zu seinem eigenen Tod, seinem Selbstmord, verfolgenden Frage zu tun, welche die Welt in Weiß und Schwarz einteilt und alles nur mit diesen Farben identifiziert sehen will. Die Scheidung dazwischen charakterisiert - wie wir sahen - die vom Erzähler vorgenommene historische Situierung des Geschehens im Kontext von Dessalines Marsch auf Port-au-Prince. Diese Zweiteilung aber reicht, wie sich bald zeigen wird, weder aus, um die eigene Situation adäquat zu begreifen, noch dafür hin, das eigene Überleben des aus einem gänzlich anderen Kulturkreis stammenden Fremden abzusichern. Gemeinsam mit diesem Kleist'schen Protagonisten muss die Leserschaft lernen, dass die Welt nicht in schwarz und weiß eingeteilt werden kann.

Kein Wunder also, wenn die Selbstbezeichnung Babekans als Mulattin und die Bezeichnung ihrer Tochter - nun nicht mit der Stimme des Erzählers, sondern der Mulattin selbst - als „Mestize“72 den jungen Schweizer Gustav verwirrt und in große Unsicherheit stürzt. Doch als er - von Nanky, einem unehelichen Sohn Congo Hoangos, über die neuen Besitzverhältnisse im Herrenhaus aufgeklärt die Flucht ergreifen will, hält Toni ihn in ihrer Eigenschaft als Lockvogel zurück, indem sie ihr Gesicht geschickt mit einer Laterne weiß beleuchtet. Die Frage, mit der er sich an ,ihre junge liebliche Gestalt“"73 wendet, wird er bis zu ihrem wie zu seinem eigenen Tode nicht beantworten können: „Wer bist Du?“74

Toni gelingt es, den Weißen „mit sich fortzureißen“75 und mit sich an der Hand ins Innere des Hauses hineinzuziehen. Die junge Frau spielt die ihr von Congo Hoango und Babekan zugewiesene Rolle ihres Lebens und ihres Todes ihre Rolle als Lockvogel, um Weiße im Hause festzuhalten, wo Congo Hoango sie in Seelenruhe ermorden kann - mit großer Perfektion und routiniert. Hier ist sie noch Teil einer perfekten Maschinerie des Todes. Und doch ist in ihrem Fortreißen schon ein Fortgerissen-Sein, mischt sich in ihre Lockungen doch auch die so ambivalente Rede von einem schwarzen „Wütherich“, der in der Tat den Namen

72 Ebda.

73 Ebda., S. 15.

74 Ebda.

75 Ebda. 
Congo Hoango führe, ${ }^{76}$ der aber derzeit nicht im Hause sei, da er die Armee Dessalines mit Blei und Pulver versorge. Die Koinzidenz des zufälligen Zusammentreffens von Toni und Gustav beginnt, sich auf die Möglichkeiten und Risiken einer künftigen Konvivenz zu öffnen. Doch all dies spielt sich vor dem Hintergrund äußerster Gefahr, im Angesicht eines Spiels um Leben und Tod ab, von dem die Protagonisten freilich noch nicht wissen, dass die Liebe dafür das auslösende Moment sein wird.

Rasch will der Fremde, der sich selbst als Gustav von der Ried und „Offizier von der französischen Macht, obschon [...] kein Franzose“"77 zu erkennen gibt, seinen Weg von Fort Dauphin, wo alle Weißen ermordet worden seien, „mitten durch ein in Empörung begriffenes Mohrenland“ hindurch (so Babekan ${ }^{78}$ ) nach Port-au-Prince fortsetzen. Er will dies nicht allein, sondern gemeinsam mit einem aus zwölf Menschen bestehenden Tross, zu dem auch sein Oheim Strömli, dessen Frau und fünf Kinder gehören. Dies alles vertraut der Schweizer hoffnungsvoll der alt gewordenen Mulattin Babekan an, weil ihm „,aus der Farbe“ ihres Gesichts „ein Strahl von der meinigen“ entgegenschimmert. ${ }^{79}$ Gustavs Farbenlehre ist noch zu simpel, um sich in dieser Welt zurechtfinden zu können.

Diese Welt ist eine zwar nicht geographisch, aber militärisch, ökonomisch und sozial perfekt in sich abgeschlossene Insel, die von allem Äußeren isoliert scheint. Wiederholt wird die teils von Plantagen genutzte, teils unbebaute wilde Landschaft einer Insel, eines Eilandes heraufbeschworen, wobei die Inselhaftigkeit hier als Isolation erscheint, als ein Gefängnis, aus dem man sich allein durch Flucht vor dem Tode retten kann. Innerhalb dieser in sich abgeschlossenen InselWelt bildet das Haus, aus dem sich Gustav für sich und die Seinen Rettung erhofft, eine Insel der Zuflucht innerhalb eines den Weißen feindlich gesonnenen Landes, wobei dieses Haus von Beginn an aus vektorieller Sicht quasi als Romanfigur erscheint. Es bildet den Knotenpunkt innerhalb einer von revolutionären Bewegungen erschütterten Insel, ist selbst ein Zeugnis jenes Umsturzes der Verhältnisse, welcher in der Ermordung des Sklavenhalters und seiner Familie gipfelte, liegt zugleich aber an der großen Landstraße, die allein noch den Zugang zur allerletzten Zufluchtsinsel der Weißen ermöglicht: der vom Rest der französischen Truppen gesicherten Hafenstadt Port-au-Prince. Der Raum des vektoriellen und belebten Hauses ist folglich nicht statisch, sondern ein hochgradig vektorisierter Bewegungsraum, in dessen Inselhaftigkeit sich alle historischen, politischen

76 Ebda.

77 Ebda., S. 17.

78 Ebda.

79 Ebda., S. 18. 
und zwischenmenschlichen Bewegungen überkreuzen: In ihm ist die Geschichte Saint-Domingues und Haitis ablesbar.

Im Zeichen von Leben und Sterben darf in dieser romantischen Erzählung auch die Liebe nicht fehlen: Ihr fällt vielmehr schon vom Titel an die zentrale Rolle zu. Überraschend schnell wird dieses Haus zum Vektorenfeld der Liebe, die sich in den Augenblicken höchster Bedrohung zwischen Gustav und Toni anbahnt. Mehr noch: Die Todesgefahr erotisiert das Leben, Eros und Thanatos geben sich die Hände. Mit der „lieblichen jungen Mestize, die mir das Haus aufmachte“ ${ }^{80}$ verbindet Gustav von Beginn an ein Begehren, das schon nach wenigen Stunden im offenen Innenraum des Hauses in Lust umschlägt. Schlang Gustav früh schon bei dem von Toni zubereiteten Gastmahl seinen „Arm sanft um ihren Leib“, wobei „er sie lebhaft an seine Brust drückte“, 81 so wird sie ihrerseits dieses Begehren schnell erwidern. Und doch hatte sie ihn eben noch als Lockvogel, gleichsam als Femme fatale, ins Verderben ziehen wollen. Die Frage nach ihrer Identität, die Frage, wer sie denn sei, bleibt lange Zeit und bis an ihr Lebensende ungeklärt.

Zwischen die Nacht der Begegnung und die Nacht der Liebe eingeschoben aber ist die Toni von Gustav erzählte Geschichte von jenem „Mädchen“ vom „Stamm der Negern“, das zum Zeitpunkt des Aufstands „an dem gelben Fieber“ erkrankt war, welches „zur Verdoppelung des Elends in der Stadt ausgebrochen war“. ${ }^{82}$ Die Geschichte dieser schwarzen Sklavin bildet aus narratologischer Sicht ihrerseits eine Verdoppelung, insofern im Bezug zum narrativen Hauptstrang bereits die Farbe Gelb eine direkte Verbindung zwischen dieser von ihrem ehemaligen Herrn misshandelten Sklavin und der schönen Toni mit ihrer ins Gelbliche spielenden Hautfarbe herstellt. Aus Rache lockt die Sklavin ihren früheren Herrn ins Haus, gibt sich scheinbar seinen Liebkosungen hin, schleudert ihm dann aber voller Wut im Bett entgegen: „Eine Pestkranke, die den Tod in der Brust trägt, hast du geküßt: geh und gieb das gelbe Fieber allen denen, die dir gleichen!“"83

Die figurale ${ }^{84}$ Komposition dieser eingeschobenen Mikroerzählung als Verdoppelungsstruktur wird nicht nur durch das Element des Hauses oder die Farbe Gelb, sondern auch durch die Brust als Ort des Todes betont - wird Gustav später Toni doch nicht zufällig in die Brust, ins liebende Herz schießen. Darüber hinaus führt das Gelbfieber, das die Leitepidemie der zweiten Phase beschleunigter

\footnotetext{
80 Ebda., S. 20.

81 Ebda., S. 36.

82 Ebda., S. 31.

83 Ebda., S. $32 \mathrm{f}$.

84 Zum Begriff der figura vgl. Auerbach, Erich: Figura. In (ders.): Gesammelte Aufsätze zur romanischen Philologie. Herausgegeben von Fritz Schalk und Gustav Konrad. Bern - München: A. Francke Verlag 1967, S. 55-93.
} 
Globalisierung ist (so wie die Immunschwächeerkrankung Aids für den Beginn und Covid-19 für den Abschluss der vierten Phase paradigmatisch stehen), jene Imaginationen fort, die sich an die Leitepidemie der ersten Phase beschleunigter Globalisierung knüpften.

Denn an der Wende zum 16. Jahrhundert hatten die Europäer - wie es in vielen späteren Darstellungen heißt - als Rache für den von ihnen an der indigenen Bevölkerung verübten Genozid von Indianerinnen die Syphilis empfangen, eine Seuche, die rasch - wie etwa Cornelius de Pauw in seinen überaus einflussreichen Recherches philosophiques sur les Américains betonte - auf die Alte Welt übergegriffen hatte. Der Zusammenhang zwischen den von Weißen verübten Gräueltaten, der Rache der Natur und der lustvollen Vereinigung mit doppelt kolonisierten abhängigen Frauen erweist sich im Vergleich mit dieser 1768 erstmals in Berlin veröffentlichten Schrift des Amsterdamer Philosophen als eine offenkundige Deutungslinie, deren Spur die verschiedensten Phasen beschleunigter Globalisierung bis in unsere Zeit durchzieht:

\begin{abstract}
Nach dem raschen Massaker an einigen Millionen von Wilden fühlte sich der erbarmungslose Sieger von einem epidemischen Übel befallen, welches zugleich die Prinzipien des Lebens \& die Quellen der Zeugung befiel und dadurch bald schon zur schrecklichsten Geißel der bewohnbaren Welt wurde. Der schon allein von der Last seiner Existenz niedergedrückte Mensch fand zu seinem höchsten Unglücks die Keime des Todes in den Armen der Lust \& am Busen der Wollust vor: Er glaubte sich ohne alle Hilfe verloren: Er glaubte, die erregte Natur habe ihm seinen Untergang geschworen. ${ }^{85}$
\end{abstract}

Cornelius de Pauw formuliert Schreckensbilder, die jegliche mit dem Körper und dessen sexueller Dimension verbundene Epidemie begleiten: In den Armen der Lust, an den Brüsten der Wollust lauert die Gefahr tödlicher Ansteckung. Die Semantisierung gerade des Körpers der Frau ${ }^{86}$ besitzt eine lange koloniale Vorgeschichte, ${ }^{87}$ auf die auch Heinrich von Kleist in seiner Meistererzählung aufmerksam macht. Die namenlose schwarze Sklavin, deren Geschichte von Gustav erzäh-

85 Pauw, Cornelius de: Recherches philosophiques sur les Américains, ou Mémoires intéressants pour servir à l'Histoire de l'Espèce humaine. 2 Bde. Berlin: Chez Georges Jacques Decker, Imp. du Roi 1768-1769, hier Bd. I, S. a3v. Vgl. in diesem Zusammenhang auch Ette, Ottmar: „Not just brought about by chance“: reflections on globalisation in Cornelius de Pauw and Alexander von Humboldt. In: Studies in Travel Writing (Nottingham) XV, 1 (February 2011), S. 3-25.

86 Vgl. hierzu Weigel, Sigrid: Der Körper als Kreuzpunkt von Liebesgeschichte und Rassendiskurs in Heinrich von Kleists Erzählung „Die Verlobung in St. Domingo“. In: Kleist Jahrbuch (Stuttgart - Weimar) (1991), S. 202-217.

87 Vgl. hierzu Hölz, Karl: Das Fremde, das Eigene, das Andere. Die Inszenierung kultureller und geschlechtlicher Identität in Lateinamerika. Berlin: Erich Schmidt Verlag 1998. 
lerisch eingeblendet wird, konfiguriert in einer ersten Verdoppelungsstruktur die männlichen Ängste, die sich für den Schweizer mit dem weiblichen Hereinlocken ins Haus und mit der als Lockvogel so effizienten Mulattin verbinden. Gustav ist hin- und hergerissen: Er weiß nicht, wie er sich verhalten soll.

$\mathrm{Zu}$ allem Unglück verbindet sich diese Unsicherheit auch noch mit den Schreckensbildern einer den Mann beim Akt der Liebe befallenden epidemischen Krankheit. Nicht zufällig wird Gustavs vollständige Verwirrung im klug aufgebauten Handlungsablauf mit der Gefahr einer Ansteckung durch Gelbfieber gekoppelt, hatte Kleist diese um sich greifende Krankheit der „fièvre jaune“ doch in seinem im Januar 1811 in den Berliner Abendblättern veröffentlichten Artikel Kurze Geschichte des gelben Fiebers in Europa mit dem Begriff einer „occidentalischen Pest“ belegt. ${ }^{88}$ Kleist wusste also, wovon er sprach, als er das Gelbfieber, das gelbe Fieber, in seine Erzählung einschmuggelte.

Seine medizinhistorisch angelegte kurze Studie, die wenige Wochen vor der ersten Veröffentlichung der hier untersuchten Erzählung erschien, hatte insbesondere die großen Gelbfieber-Epidemien von 1793 und 1804 beleuchtet, die beide nicht von ungefähr in den Zeitraum der Haitianischen Revolution und damit in die Diegese von Die Verlobung in St. Domingo fallen. Kleists Überlegungen dokumentieren sein geschärftes Bewusstsein dafür, wie sehr das Gelbfieber zu einer Krankheit, einer Seuche, einer Epidemie, ja einer Pandemie geworden war, wobei sich der Schriftsteller nicht nur für die Symptomatik dieser „occidentalischen Pest“, sondern auch für deren weltweite Verbreitung interessierte. Kleists Erzählung spielt immer wieder mit Phänomenen von welthistorischer Bedeutung - und wie sehr eine Pandemie weltgeschichtliche Bedeutung erlangen kann, bekommen wir derzeit gerade durch den Corona-Virus anschaulich vor Augen geführt.

Der Ausbruch des Gelbfiebers bei den französischen Truppen unter General Leclerc - der selbst dieser Krankheit im Verlauf des Krieges bereits am 1. November 1802 erlag - darf auf Ebene des historischen Hintergrundes durchaus als wichtiges, vielleicht sogar kriegsentscheidendes Ereignis angesehen werden. Eine Übertragung auf die Handlungsebene der Erzählung erfolgt auch insoweit, als es der „Officier“ Gustav ist, der Toni befragt, „ob sie wohl einer solchen That fähig wäre“. ${ }^{89}$ Auch wenn Toni die Frage klar verneint: Als Gustav in das ihm

88 Vgl. Kleist, Heinrich von: Kurze Geschichte des gelben Fiebers in Europa. In: Berliner Abendblätter (Berlin) 19 und 20 (23. Januar und 24. Januar 1811), S. 73-75 und 77-79, hier S. 78. Vgl. hierzu Loster-Schneider, Gudrun: Toni, Babekan und Homi Bhabha? Zu Problemen kultureller und ästhetischer Hybridisierung in Heinrich von Kleists „Die Verlobung in St. Domingo“, S. 239.

89 Kleist, Heinrich von: Die Verlobung in St. Domingo, S. 33. 
angewiesene Zimmer tritt, das zuvor wohl Guillaume von Villeneuve gehört hatte, bemerkt er deutlich, wie sich „ein Gefühl der Unruhe wie ein Geyer um sein Herz“ legte. ${ }^{90}$ Doch der Blick auf die „dunklen Locken“ und „die jungen Brüste“ des Mädchens, ${ }^{91}$ das die Fußwaschung des fremden Gastes vorbereitet, lenkt Gustav von allen Todesahnungen ab und heitert ihn wieder auf. Gerade in der Todesgefahr entfaltet Eros seine Macht, denn in der Bedrohung seines Überlebens erfreut sich der junge Schweizer am Schauspiel des Lebens. Und doch gibt es, was die betörende Schönheit Tonis angeht, eine Einschränkung, denn ,er hätte, bis auf die Farbe, die ihm anstößig war, schwören mögen, dass er nie etwas Schöneres gesehen“. ${ }^{92}$ Hat sich die gelbe Hautfarbe Tonis hier nicht mit dem Gelbfieber ihrer schwarzen Figura verbunden?

Kurze Zeit später fällt Gustav eine „entfernte Ähnlichkeit“93 auf, die er zunächst nicht zu konkretisieren weiß, die aber eine zweite Verdoppelungsstruktur einleitet, in der die Figur Tonis gleichsam zwischen die Figura der schwarzen Sklavin mit Gelbfieber und die eines weißen Mädchens gestellt wird. Ein fünftes und letztes Dreieck entsteht, wodurch das Dreieck von Schwarzer, Weißer und Mulattin personalisiert wird: ein Dreieck, das mit noch ungewissen Konturen aus dem Unbewussten des jungen Schweizer Offiziers aufsteigt.

Doch schon bald wird sich die Unbekannte als niemand anderes als die unter tragischen Umständen verstorbene Braut Gustavs herausstellen. Indem der Fremde das gerade fünfzehnjährige Mädchen zu sich auf den Schoß zieht und es mit seinen Händen umfängt, entspinnt sich ein vertrautes, fast inniges Gespräch, bei dem sich Toni schließlich ,unter einem überaus reizenden Erröthen, das über ihr verbranntes Gesicht aufloderte“, ${ }^{94}$ an die Brust des fremden Mannes schmiegt. Nach einem ersten scheuen Kuss auf ihre Stirn ${ }^{95}$ erkennt er in ihr wie in einer Anagnorisis das Abbild jener jungen Frau, die sich als seine liebe Braut einst für ihn aufgeopfert hatte. Erneut wird Toni mit dem Tode konnotiert, freilich mit dem Tode einer anderen, einstmals geliebten Frau.

Die eingeflochtene Mikroerzählung um die aus Straßburg stammende Mariane Congreve, Gustavs geliebte Braut, die einst an seiner statt unschuldig guillotiniert worden war, stellen das Bild von Toni zwischen jene der schwarzen Sklavin und der weißen Verlobten, so dass die Mulattin als zwischen beiden Polen

\footnotetext{
90 Ebda., S. 35.

91 Ebda.

92 Ebda., S. 36.

93 Ebda.

94 Ebda., S. 38.

95 Ebda., S. 39.
} 
oszillierendes Objekt männlicher Begierde in den Vordergrund rückt. Wie die namenlose Sklavin erscheint auch das Bild der Mariane Congreve als das einer todgeweihten Frau, eine (da stets von Gustav erzählte) männliche, nur über ihre schöne Leiche ${ }^{96}$ vermittelbare Projektion von Frauenbildern, die sich dank der bereits erwähnten figuralen Überlagerung notwendig auch auf Toni überträgt. Toni steht im Zentrum aller figuralen Projektionen, die den gesamten Text der Erzählung durchziehen.

Wie aber war die Braut des jungen Schweizer zu Tode gekommen? Wir können diese Ereignisse, in die Gustav schuldhaft verstrickt ist, kurz zusammenfassen: Hatte sich Gustav unbesonnen kritisch über das Revolutionstribunal der jüngst errichteten Französischen Revolution geäußert, so wurde Mariane anstelle ihres flüchtigen Bräutigams hingerichtet - nicht ohne dem entsetzten Gustav, der sie nicht mehr zu retten vermag, vom Schafott aus einen letzten, sich unauslöschlich einprägenden Blick zuwerfen zu können. ${ }^{97}$ Mariane opferte sich auf, indem sie öffentlich verleugnete, den schuldlos schuldig gewordenen Gustav überhaupt zu kennen. Und wird sich Toni nicht verleugnen, um sich und Gustav doch noch vor dem Verrat zu retten? Im Kleist'schen Spiel von Täuschungen und Verstellungen behält jedoch der Tod zumeist das letzte Wort und löst alle Verstrickungen mit der Vernichtung aller Gestalten auf.

Doch blicken wir zunächst auf das entscheidende Geschehen der Erzählung! Denn erst jetzt, nach der verdoppelten Verdoppelung, kann der Erzähler von der Liebesnacht berichten. Indem Toni ihre Tränen um Mariane Congreve mit den Tränen Gustavs mischt, ${ }^{98}$ lässt sie die Körperflüssigkeiten beider in einer allzu kurzen Liebesnacht zusammenfließen und tritt zugleich das figurale Erbe der hingerichteten Straßburger Braut an. Wird Gustav nicht auch ihr den Tod bringen? Zunächst ist es nur der ,kleine Tod' der gemeinsamen Liebesnacht.

Die früh schon angelegte Zwischenstellung der Mulattin erfüllt sich in einer Vereinigung, die in der Mitte der Erzählung nur durch Schweigen narrativ ausgeführt werden muss: „Was weiter erfolgte, brauchen wir nicht zu melden, weil es jeder, der an diese Stelle kommt, von selbst liest.“999 Der Höhepunkt ist eine narrative Auslassung, mit welcher der Erzähler alles Imaginieren seinem Lesepublikum überlässt: Eine Ellipse steht im Mittelpunkt allen Erzählens.

96 Vgl. hierzu Bronfen, Elisabeth: Nur über ihre Leiche. Tod, Weiblichkeit und Ästhetik. München: dtv 1994.

97 Kleist, Heinrich von: Die Verlobung in St. Domingo, S. 42.

98 Ebda., S. 43.

99 Ebda. 
Danach aber sind Tonis Tränen kaum zu stillen. Die weitreichenden Folgen jener „That, die er begangen“, ${ }^{100}$ bleiben dem Schweizer zunächst noch unklar; und doch ist jene Geste, mit der er Toni das goldene Kreuz der Mariane Congreve als Geschenk übergibt, nicht nur die Übergabe eines Schmuckstücks, sondern weit mehr noch der Abschluss eines Vertrags, den Gustav ursprünglich mit seiner weißen Braut geschlossen hatte. Doch längst ist die Mulattin Toni an die Stelle der Weißen getreten.

Es ist, wie sich bald zeigen wird, ein im Verborgenen bleibender Vertrag mit der kaum fünfzehnjährigen Toni, mit dem ein künftiges Zusammenleben über Rassenschranken hinweg vereinbart wird. Es ist ein Pakt auf Augenhöhe, bei dem sich aber bald schon die Amerika, Afrika und Europa verbindende Antillanerin ihrem Partner als nicht nur ebenbürtig, sondern deutlich überlegen erweist. ${ }^{101}$ Denn nur durch ihre List eröffnet sich die Chance, der kolonialen Last eine künftig zu genießende Lust entgegenzustellen. Eine noch vor kurzem kaum vorstellbare Konvivenz über alle Rassenschranken des europäischen Kolonialismus hinweg deutet die revolutionäre Stoßrichtung dieser Vision eines glücklichen Zusammenlebens in der Zukunft an.

Dass Mariane Congreve aus Straßburg, jener „Stadt der sich kreuzenden Straßen" stammt, ist deshalb wohl kein Zufall, weil auch ihre Erbin Toni ihrem Haus an der großen Landstraße die Zufallsbegegnung mit Gustav von der Ried verdankt. Beide Begegnungen stehen im Zeichen des Transitorischen, eines Transits, von dem nicht anzunehmen war, dass jemals eine Verstetigung des nur vorübergehenden Zusammenlebens denkbar wäre. Urplötzlich aber erscheint das kaum Imaginierbare, kaum Denkbare, als etwas, das lebbar ist und gelebt werden kann: Eine ungeheure Revolution deutet sich an. Doch wie wäre mitten im militärischen Konflikt der kolonialen Gegenspieler, mitten in der Zerreißprobe unterschiedlicher Geschlechteridentitäten und ethnischer Herkünfte damit ernsthaft $\mathrm{zu}$ rechnen, dass allen Exklusionen, Ausgrenzungen und Massakern zum Trotz die Chance auf ein Zusammenleben bestünde? Ist das Spiel, auf das sich Toni und Gustav eingelassen haben, nicht von Anfang an ein verlorenes Spiel?

Mag sein! Doch Kleist lässt sie es im Erprobungsraum seiner Erzählung durchspielen und durchleben. So erst wird Die Verlobung in St. Domingo zum vielstimmigen Experimentierraum eines Zusammenlebens, das im Grunde keine

100 Ebda.

101 Vgl. hierzu auch Fleming, Ray: Race and the Difference It Makes in Kleist's „Die Verlobung in St. Domingo“. In: The German Quarterly (Riverside, California) LXV, 3-4 (summer - fall 1992), S. 306-317. 
Chance auf Zukunft haben dürfte. Das „Brautgeschenk“102 macht klar, dass die geschlechtliche Vereinigung von Weißem und Mulattin, von Kolonialherrn und kolonisierter Frau, eine riskante Verlobung darstellt, die nur durch das Projekt künftigen Zusammenlebens die tradierte patriarchalische Verfügbarmachung der Mulattin für die männliche Lust institutionell zu unterlaufen in der Lage wäre. Denn ist nicht die Schwarze zur Arbeit, die Weiße zur Heirat, die Mulattin aber für die rasche sexuelle Befriedigung da?

Der zwischen Gustav und Toni vereinbarte Vertrag, ihre ,Verlobung،, hält gegen diese kolonialistische Pflanzer-Ideologie Gustavs Versprechen, schon am nächsten Morgen bei der Mutter um ihre Hand anzuhalten, und geht sofort über in die Vision künftiger Konvivenz:

Er beschrieb ihr, welch ein kleines Eigenthum, frei und unabhängig, er an den Ufern der Aar besitze; eine Wohnung, bequem und geräumig genug, sie und auch ihre Mutter, wenn ihr Alter die Reise zulasse, darin aufzunehmen; Felder, Gärten, Wiesen und Weinberge; und einen alten ehrwürdigen Vater, der sie dankbar und liebreich daselbst, weil sie seinen Sohn gerettet, empfangen würde. ${ }^{103}$

Diese Vision lässt einen Anderort, eine idyllische Heterotopie entstehen, die alle Züge eines Lustorts, eines „locus amoenus“, trägt. Es ist die Idylle einer von Privatbesitz und patriarchalischer Güte geregelten Welt, die sich der Raserei und Mordlust einer aus den Fugen geratenen kolonialen Welt dezidiert entgegenstellt. Schwört Gustav seiner Toni auch, er habe nur „im Taumel wunderbar verwirrter Sinne, eine Mischung von Begierde und Angst, die sie ihm eingeflößt“"104 und nicht aus männlichem Kalkül von ihr Besitz ergriffen, so ist sein Gegenbild einer auf Dauer gestellten ehelichen Verbindung doch wohlkalkuliertes Zeugnis einer rational entworfenen Welt. Diese stellt ihrerseits eine kleine, in sich abgeschlossene Insel bürgerlicher Glückseligkeit dar, die in schärferem Kontrast zur Situation in Saint-Domingue kaum stehen könnte. Die schweizerische Idylle tritt in Wettstreit mit der blutigen Realität der Haitianischen Revolution.

Und doch schleicht sich in diese Idylle auf höchst ambivalente Weise ein nicht unwesentliches Stückchen Saint-Domingue ein - auch an dieser Stelle erweist sich die erzählerische Meisterschaft eines Heinrich von Kleist. Denn wird hier die Mulattin nicht von Gustavs Vater aus Dankbarkeit dafür mit der Aufnahme in die Familie geehrt, seinem Sohn das Leben gerettet zu haben? Wird somit nicht in einer weiteren Verdoppelungsstruktur das Zeichen großer Dankbarkeit ganz so

102 Kleist, Heinrich von: Die Verlobung in St. Domingo, S. 43.

103 Ebda., S. 44.

104 Ebda. 
als patriarchalische Wohltat zelebriert, wie einst Congo Hoango für die Errettung seines Herrn mit Freilassung, finanziellen Mitteln, der mulattischen Lebenspartnerin Babekan und einer Inklusion in den Kreis derer belohnt wurde, die Befehlsgewalt über Sklaven ausüben dürfen? Es scheint daher nicht übertrieben zu behaupten, dass sich in Gustavs glückliche Vision künftiger Konvivenz ein kolonialer Geburtsfehler eingeschlichen hat, der die Mulattin Toni noch in der Schweiz mit jenen Asymmetrien konfrontiert, die sie am liebsten doch gänzlich hinter sich gelassen hätte, aber doch nicht hinter sich lassen kann.

Gleichwohl ist Gustavs schweizerische Idylle das Gegenbild zu einer kolonialen Gesellschaft, deren Kollaps zuvor schon in ein gewalttätiges, nicht stillzustellendes, da sich zerstückelndes Körperbild ${ }^{105}$ übersetzt worden war: „Ist es nicht“, so hatte Babekan gesagt, „als ob die Hände Eines Körpers, oder die Zähne Eines Mundes gegen einander wüthen wollten, weil das Eine Glied nicht geschaffen ist, wie das andere?"106 In der Gesellschaft der gnadenlosen europäischen Sklavenhalter wie in der Gegen-Gesellschaft einer Haitianischen Revolution, welche die Polung einer von Rassenhierarchien geprägten Gemeinschaft nur umkehrt, stehen sich in Kleists Erzählung in spiegelsymmetrischer Ausschließlichkeit Mechanismen der Exklusion blutrünstig gegenüber, die auch den eigenen Körper im Bild des in sich selbst zerbissenen und zerrissenen Leibes nicht verschonen. Die Metaphorologien der körperlichen Selbstzerfleischung entwerfen ein anschauliches, plastisches Bild von den Zerstörungs- und Selbstzerstörungskräften der Revolution.

Gegen alle Schreckensbilder setzt Gustav von der Ried - der nicht umsonst mit Herrn von Villeneuve (aber auch mit Kleist) den Adelstitel teilt - die schweizerische Vision einer Inklusion, die in besonderer Weise den Einschluss der schönen Mulattin in den Kreis der Familie vornimmt. Damit wird eine die Rassenschranken transgredierende Verbindung zwischen dem weißen Offizier und der hellhäutigen Mulattin konkret vorstellbar, so dass sich an dieser Stelle der Erzählung, nach der sexuellen Vereinigung von Toni und Gustav, ein alternatives Modell für ein Zusammenleben zwischen verschiedenen ethnischen Gruppen abzuzeichnen beginnt. Dies ist das eigentlich aufleuchtende Versprechen der Verlobung - wenn auch nicht Hochzeit - in St. Domingo. Denn zu einer ehelichen Verbindung wird es niemals kommen.

105 Vgl. zum zerstückelten Körper bei Kleist die Überlegungen in Jauß, Hans Robert: Befragung des Mythos und Behauptung der Identität in der Geschichte des „Amphitryon“. In (ders.): Ästhetische Erfahrung und literarische Hermeneutik. Frankfurt am Main: Suhrkamp 1982, S. 534-584. 106 Kleist, Heinrich von: Die Verlobung in St. Domingo, S. 19. 
Gewiss ist dieses die Rassenschranken ignorierende Modell in eine ferne Schweiz verlegt, in der die Felder, Gärten, Wiesen und Weinberge eine Landschaft der Theorie entwerfen, in der im Zeichen allgemeiner Fruchtbarkeit die Gegensätze nicht länger unvermittelt aufeinanderprallen, sondern lieblich ausgeglichen werden. Die Landschaft gibt diese Ziel- und Wunschvorstellung in ihrer Anlage selbst kund. Konvivenz zwischen verschiedenen Geschlechtern und Ethnien, unterschiedlichen Kulturen und Klassen wird vorstellbar, auch wenn Kleists Erzählung am Beispiel der Haitianischen Revolution vorführt, wie weit der Weg bis zur Verwirklichung einer derartigen Vorstellung friedlichen Zusammenlebens - und sei es noch so patriarchalisch eingefärbt - noch immer ist. Die Liebe bildet hier gewiss ein stets prekäres Bewegungsmittel, kann sie doch auch bei Missverständnissen in Hass umschlagen, der sich - wie Kleist in seiner Erzählung eindrucksvoll vorführt - ebenso zerstörerisch wie selbstzerstörerisch auswirkt. Und doch: Es zeichnet sich zwischen beiden Liebenden eine Verlobung ab, die für die Zukunft nicht nur Glück, sondern gelebte Konvivenz verspricht.

Das in Die Verlobung in St. Domingo polylogisch entfaltete ZusammenLebensWissen ${ }^{107}$ entwirft ein hintergründiges, gewiss auch tragisch eingefärbtes Bild von Konvivenz auf individueller wie kollektiver Ebene. Es geht in diesem Prosastück um die Möglichkeiten wie die Grenzen des Zusammenlebens in einer vom europäischen Kolonialismus noch immer geprägten Welt. Dabei ist es faszinierend zu sehen, wie Heinrich von Kleist die Modernität seines Blickes nicht nur - wie die meisten seiner deutschen Zeitgenossen - mit einem kritischen Rückblick auf die europäische Doppelrevolution schärft und historisch auflädt. Er beschränkt sich nicht auf die Einbeziehung von Reflexen der von Frankreich ausgehenden politischen und der von England ausgehenden industriellen Revolution, sondern bietet seinen Lesern eine welthistorische Dimension, indem er die Haitianische Revolution im Kreuzungspunkt verschiedenster Diskurse zum Reflexionsort seiner verzweifelten Liebesgeschichte macht. Allein schon der Schritt aus Europa heraus hin zur Kulisse der Haitianischen Revolution ist ein gewagter, unter mancherlei Gesichtspunkten sogar revolutionärer Schritt. Bringt nicht die Antriebskraft der Liebe all jene widersprüchlichen Faktoren zum Vorschein, die von entscheidender Bedeutung sind für ein Zusammenleben im weltweiten Maßstab, eine Konvivenz, die sich gerade nicht auf eine Schweizer Idylle beschränkt wissen will?

Die Vergangenheit der Tyrannei einer erbarmungslosen Plantagenwirtschaft wie die Gegenwart einer gewaltsamen, grausamen Befreiung ihrer Opfer hält beide Liebende fest in ihren Krallen. Gustav macht gegenüber Toni deutlich, dass

$107 \mathrm{Zu}$ diesem Konzept vgl. Ette, Ottmar: ZusammenLebensWissen. List, Last und Lust literarischer Konvivenz im globalen Maßstab (ÜberLebenswissen III). Berlin: Kulturverlag Kadmos 2010. 
er das „allgemeine Verhältniß“ der Weißen zu den Schwarzen - womit er euphemistisch die Sklaverei bezeichnet - nicht vorbehaltlos „in Schutz zu nehmen“ gewillt ist. ${ }^{108}$ Doch seien Missetaten ,vielfacher und tadelswürdiger Mißhandlungen“ nur „von einigen schlechten Mitgliedern“ der Zuckeroligarchie begangen worden, ${ }^{109}$ so dass all dies den „Wahnsinn der Freiheit“ und die Racheaktionen der Schwarzen an den Weißen für deren „schon seit vielen Jahrhunderten“ bestehendes System ${ }^{110}$ nicht rechtfertigen könne. Wie hätten die Sklaven, wie hätte eine Babekan, die nicht nur vom Vater ihrer Tochter verleugnet, sondern auch von Herrn von Villeneuve misshandelt und ausgepeitscht wurde, ${ }^{111}$ einer derartigen Einschätzung zustimmen sollen?

In der Erzählung werden unter der Stimme des Erzählers viele unterschiedliche Diskurse hörbar, so dass man im Sinne des russischen Literaturtheoretikers Michail M. Bachtin ${ }^{112}$ sicherlich von einem Kosmos der Redevielfalt sprechen kann, der auf die Herausforderungen der zweiten Phase beschleunigter Globalisierung höchst sensibel reagiert. Heinrich von Kleist ist es in Die Verlobung in St. Domingo gelungen, aus dieser Rede- und Stimmenvielfalt einen literarischen Erprobungsraum zu modellieren, in dessen Mittelpunkt es um die Frage nach den Chancen, aber auch den Risiken und Gefahren künftigen Zusammenlebens im weltweiten Maßstab geht.

Heinrich von Kleists Erzählung entfaltet so ein breit angelegtes ZusammenLebensWissen, das von keiner einzelnen Erzählerstimme in seiner Bedeutungsvielfalt begrenzt oder beschnitten werden kann. Die polylogische, vielen verschiedenen Logiken zugleich verpflichtete erzählerische Strukturierung führt die unterschiedlichen und gegenläufigen Perspektiven vor, die im Brennspiegel der Haitianischen Revolution gewaltsam aufeinanderprallen. Nicht nur für Humboldt, sondern auch für Kleist wird Haiti zur Herausforderung, ja zum Paradigma, an dem sich Zukunft im globalen Kontext nicht nur abschätzen, sondern auch narrativ erproben lässt. Wie stark und zerstörerisch dieser Zusammenprall in der zweiten Hälfte der Erzählung auch immer sein mag: Er vermag nicht zu verdecken, was man die prospektive, auf künftige Konvivenz gerichtete Dimension der Kleist'schen Erzählung nennen muss. Die kommende Katastrophe löscht das Bild künftiger Konvivenz nicht aus.

108 Kleist, Heinrich von: Dioe Verlobung in St. Domingo, S. 31.

109 Ebda.

110 Ebda.

111 Ebda., S. 29.

112 Vgl. Bachtin, Michail M.: Das Wort im Roman. In (ders.): Die Ästhetik des Wortes. Herausgegeben von Rainer Grübel. Frankfurt am Main: Suhrkamp 1979, S. 154-300. 
Erscheint die schöne Mulattin am Ende der ersten und einzigen Liebesnacht „wie eine Leblose“113 - ein kleiner Tod, der schon auf den großen vorausweist -, so bringt der neue Tag Babekans Plan an die Oberfläche: Sie will die Reisegesellschaft der Weißen durch Täuschung und Verstellung noch so lange festhalten, bis Congo Hoango diese weißen oder kreolischen Halbhunde, wie er sie nennt, ${ }^{114}$ wie so viele vor ihnen ihrem verdienten Schicksal zuführen könne. ${ }^{115}$ Das Bild der Lust wird von der lebensbedrohlichen Last, das Bild heterotoper Konvivenz von jenem topischer Konfrontation verdrängt: Alles droht, in einer einzigen großen Katastrophe zu versinken. Mit Hilfe welcher neuen List aber könnte es gelingen, eine auf Dauer gestellte Lust der Konvivenz wiederzugewinnen?

Toni begehrt augenblicklich gegen den Plan ihrer Mutter auf, durch ein System wohlkalkulierter Lügen das „Haus“ - wie schon zu oft - in eine Falle, in eine „Mördergrube“ zu verwandeln. ${ }^{116}$ Ihre Liebe lässt sie erfinderisch werden. Doch Babekan verweist auf frühere Beispiele, wie man nicht nur Franzosen, sondern auch Portugiesen oder Holländer (und damit die Repräsentanten anderer europäischer Kolonialmächte) erfolgreich zur Strecke gebracht habe ${ }^{117}$ - ganz unabhängig von einer jeweils individuellen Schuld, und ohne, dass man ihnen etwas Konkretes hätte „zur Last“ legen können. ${ }^{118}$ Doch es geht hier nicht um individuelles Verhalten, sondern um die blutige Rache an einem mörderischen System, das auf einem Gegensatz der Hautfarben beruhte. Toni aber möchte von der Mutter nicht mehr an „diese Gräuelthaten“ erinnert werden, habe sie sich doch längst dagegen empört, zur Teilnahme an diesen geradezu rituell verübten Morden gezwungen $\mathrm{zu}$ werden. ${ }^{119}$ So stellt sich die junge Frau schützend vor den Schweizer, schwört, lieber „zehnfachen Todes“ zu sterben, als mitansehen zu müssen, wie Gustav auch nur ein Haar gekrümmt werde. ${ }^{120}$

Dann aber wechselt Toni ihre Taktik und greift $\mathrm{zu}$ einer neuen List, indem sie scheinbar auf die Vorschläge der Mutter eingeht. Babekan aber schöpft Verdacht und fragt, was Toni denn zuvor in einer einzigen Nacht bewogen habe, so grundlegend ihre Meinung zugunsten des Fremden zu ändern. ${ }^{121}$ Denn auch für Babekan bildet diese Nacht - die Liebesnacht von Toni und Gustav - eine schwer

113 Kleist, Heinrich von: Die Verlobung in St. Domingo, S. 45.

114 Ebda., S. $21 \mathrm{f}$.

115 Ebda., S. 46.

116 Ebda., S. 47.

117 Ebda., S. $48 \mathrm{f}$.

118 Ebda., S. 49.

119 Ebda., S. 49.

120 Ebda.

121 Ebda., S. 52. 
aufzulösende Ellipse. Die Tochter aber hat sich fest auf ihre List verlegt und hebt hervor, beim Anblick ihrer Mutter sei ihr erst wieder „die ganze Unmenschlichkeit der Gattung, zu der dieser Fremde gehöre“, klar vor Augen getreten. ${ }^{122}$ Denn Babekans Körper zeigt noch immer alle Zeichen ihrer durch die Kolonialherren erlittenen Misshandlungen: An ihrem geschundenen Körper werden sämtliche Gräuel eines menschenverachtenden Systems lesbar.

Die List der jungen Mulattin scheint zu gelingen, kann sie doch Babekan erst einmal ruhigstellen. Für Gustav aber wird Tonis Verhalten bald schon rätselhaft. Er vermag nicht wirklich darauf zu vertrauen, was der Erzähler weiß: Dass Toni in dem gestern noch Fremden nicht mehr nur einen bloßen Gast, sondern ,ihren Verlobten und Gemahl“ erblickt. ${ }^{123}$ Doch des Erzählers Wissen ist nicht das des Schweizers: Weder versteht er noch vertraut er. Dabei ist nicht nur für Gustav, sondern auch für Toni die Verbindung nun vollzogen, ja schließt schon die Hochzeit mit dem jungen Offizier mit ein. Aus ihrer einzigen Liebesnacht ist für die junge Mulattin eine Verlobung, ja eine Vermählung geworden, so dass sie wie Mariane Congreve, die erste Braut des Schweizers, jederzeit bereit ist, ihr Leben für ihren Mann bedenkenlos zu opfern und sich hinzugeben. Gustav aber läuft gefährlich in die sich abzeichnende Falle, ein weiteres Mal seine geliebte Braut für sich aufzuopfern und am Tod beider Ehefrauen schuldig zu werden. Der Tod der jungen, liebenden Frau ist ein romantischer Topos, dem wir noch häufig im Rahmen unserer Vorlesung begegnen werden.

Mit Tonis List aber wird das Bild künftiger Konvivenz vom Anderort der Schweiz in das Hier und Heute eines Zusammenlebens in der Karibik geholt, das in seiner Existenz zutiefst bedroht ist. Und dies nicht nur von außen, von all jenen Protagonisten und Gruppen, die sich auf die erbarmungslose Jagd nach Weißen gemacht haben, sondern auch vom Innern der Beziehung selbst aus. Denn Toni hat Gustav nicht in die von ihr gewählte List eingeweiht, mit der sie die schwer auf beiden lastende tödliche Gefahr in gemeinsame Lust verwandeln will. Dies ist ein folgenschwerer Fehler, denn die Asymmetrie des Wissens wird Konsequenzen haben, welche die heraufziehende Katastrophe nahezu unausweichlich werden lassen.

Erneut wird nun das Haus zur Spielfläche einer tödlichen Auseinandersetzung und übernimmt eine aktive, die Handlung vorantreibende Rolle. Dabei steht die List der Tochter gegen die List der Mutter. ${ }^{124}$ Für ihren eigenen Plan erhofft sich Toni göttlichen Beistand, kniet sie sich doch vor dem „Bildniß der

122 Ebda., S. 52 f.

123 Ebda., S. 59.

124 Ebda., S. 62. 
heiligen Jungfrau, das neben ihrem Bette hing“, nieder ${ }^{125}$ und fleht ihren Sohn Jesus Christus ,in einem Gebet von unendlicher Inbrunst, um Muth und Standhaftigkeit an“, auch um die von ihr mitbegangenen Verbrechen, „die ihren jungen Busen beschwerten“, eingestehen zu können. ${ }^{126}$ Diese Last wiegt schwer auf ihr, doch hofft sie auf Gustavs Vergebung und darauf, dass er „sie als sein treues Weib mit sich nach Europa führen möchte“..27 So verwandelt sich das Gebet an eine allgegenwärtige Transzendenz in die Hoffnung auf eine heterotopische Konvivenz, hat Gustav von der Rieds in die Schweiz projizierter Entwurf künftigen Zusammenlebens doch bei der Mulattin offenkundig eine Wirkung ausgelöst, die wohl noch größer ist als jene der sexuellen Vereinigung. Es ist die Vision einer glücklichen Zweisamkeit mit einem Weißen, jenseits aller Rassenschranken, die auf Saint-Domingue galten. Nicht die bestehende, sondern das Geloben künftiger Konvivenz bildet den Kern einer Verlobung, die einen prospektiven Akt und Pakt darstellt, der Rassenschranken zwischen gelb und weiß überwinden will.

Auch Gustav selbst scheint diesen Pakt zu leben - freilich im Traum, in dem er öfters „mit glühenden, zitternden Lippen“ Tonis Namen flüstert, ohne vom Rufen des realen Mädchens zu erwachen. ${ }^{128}$ So kann sich Toni in Gustavs Schlafgemach nicht dazu durchringen, ,ihn aus den Himmeln lieblicher Einbildung in die Tiefe einer gemeinen und elenden Wirklichkeit herabzureißen“129 - ein folgenschwerer Fehler, da der erwachte Gustav Tonis List zu spät begreifen wird. In dieser letzten Szene vor dem Sturm leben die beiden Liebenden in zwei verschiedenen Welten, im Traum und in der Wirklichkeit, im Himmel und in elender Tiefe. Im Abgrund zwischen diesen beiden Welten, aber auch zwischen den Welten Europas und des von dort kolonisierten Amerikas, werden die beiden unrettbar als Opfer und Täter, aber auch als geopferte Täter verloren gehen.

Folglich kann das Schlafgemach im Bewegungsraum des Hauses auch nicht mehr zum Erprobungsraum ihres Zusammenlebens werden: Traum und Wirklichkeit klaffen $\mathrm{zu}$ weit auseinander. Denn schon dringt nicht mehr nur das Mondlicht, sondern auch „der Nachtwind“ durch die „geöffneten Fenster“130 ins Innere des Hauses ein, ein Eindringen, das als Hereinbrechen bald nicht mehr nur mit dem Haar auf Gustavs Stirn, sondern mit seinem ganzen Körper wie mit dem von Toni spielen wird. Das Bett wird niemals mehr zur Spielfläche ihrer Lust, sondern

125 Ebda., S. 62.

126 Ebda., S. 63.

127 Ebda.

128 Ebda., S. 64.

129 Ebda.

130 Ebda. 
der Fesselung: Von nun an beherrschen fremde Mächte ihre Körper und zerstören den einst weit geöffneten Spiel- und Erprobungsraum.

Nur wenige Zeilen später dringt Congo Hoango mit dem von ihm befehligten Hilfstrupp für General Dessalines in den soeben noch Schutz verheißenden Innenraum von Hof und Haus, ist das „Geräusch von Menschen, Pferden und Waffen“ hörbar. ${ }^{131}$ Zugleich wird deutlich, dass die Mutter die List ihrer Tochter erahnt und sie deshalb bei Congo Hoango schon als „Verrätherinn“132 denunziert. Die Würfel sind gefallen: Tonis List erreicht nicht mehr die Lust, sondern bricht unter der Last kolonialer Konfrontationen zusammen.

Doch Gefahr droht auch der prekären Einheit der Liebenden selbst. Denn darüber hinaus schwebt die Tochter Babekans in der Gefahr, dass auch Gustav selbst sie fortan „für eine Verrätherinn halten“ könnte, die im Einklang mit ihrer Mutter und Congo Hoango gehandelt hätte. ${ }^{133}$ Erneut steht die junge Mulattin zwischen zwei Polen, zwischen zwei Kräftefeldern und Gefahren. Ihre durch einen Zufall glücklich eingegebene List, Gustav noch vor Congo Hoango an Händen und Füßen rasch zu fesseln, wird bei dem Schweizer Offizier die falsche Einsicht festigen, dass Toni ihn mit ihren Reizen nur ans Bett gefesselt habe, um ihn als Weißen an die Schwarzen auszuliefern. Lustvolle Konvivenz bleibt auf den Traum beschränkt: Die Wirklichkeit erfasst die Liebenden und reißt sie mit sich in den Abgrund.

Im ehemaligen Haus des Sklavenhalters, jenem Herrenhaus, in dem Congo Hoango seinem einstigen Herrn die Kugel durch den Kopf jagte, ist an ein friedliches Zusammenleben nicht einmal mehr im Traum zu denken. Das Spiel ist aus und auch das Liebesspiel! All diese Bewegungen sind im Fraktal des nun vom ehemaligen Sklaven bewohnten Herrenhauses vektoriell gespeichert: Die Leser der Erzählung können hier all jene Bahnungen abrufen, die das Verhalten der Beteiligten mitbestimmen. Aus dem alles ergreifenden Haus mit seiner langen Geschichte der Gewalt gibt es kein Entrinnen mehr.

Projekt und Projektion der Konvivenz erweisen sich im ,Stresstest“ dieser karibischen Wirklichkeit von Saint-Domingue als Traum, der sofort in einen Albtraum umzuschlagen droht. Kleists Erzählung kostet alle Details dieses Umschlagens ästhetisch aus: Nicht nur, dass Congo Hoango, Tonis List ebenso wenig durchschauend wie Gustav von der Ried, diese als „,sein liebes Mädchen“ bezeichnet, ${ }^{134}$ womit ihre Zwischenstellung zwischen schwarz und weiß noch einmal - und

131 Ebda., S. 64.

132 Ebda., S. 65.

133 Ebda., S. 67.

134 Ebda., S. 70. 
diesmal mit Blick auf die von ihr ausgelösten Gefühlsbewegungen - hervorgehoben wird. Die Tochter Babekans wird vielmehr hart von jenen Blicken getroffen, die der noch immer ans Bett gefesselte Gustav ihr „,voll Verachtung“ zugeworfen hatte und die ihr sogleich „wie Messerstiche, durchs Herz gegangen“ waren. ${ }^{135}$ Sie fühlt zurecht, wie statt der Konvivenz die Katastrophe ständig näherkommt. ${ }^{136}$ Doch anders als Gustav ist sie in ihrem Handeln nicht gelähmt.

Denn es gelingt ihr, Strömli und seine Gemeinschaft weißer Flüchtlinge vor der Falle, der Mördergrube zu warnen, in die sich das Haus des Guillaume von Villeneuve wieder verwandelt hat. Toni ist ganz in die Rolle von Gustavs erster Braut geschlüpft und frohlockt „bei dem Gedanken, in dieser zu seiner Rettung angeordneten Unternehmung zu sterben“. ${ }^{137}$ Denn Konvivenz erscheint zunehmend weder an diesem Ort, der Insel Hispaniola, noch am anderen Ort, der Insel an der Aare, sondern nur noch in einer Transzendenz realisierbar, so dass der kleine Tod geschlechtlicher Vereinigung nur noch im großen Tod gemeinsam durcherlebt werden kann. Aus dieser stringent durchgehaltenen narrativen Logik schöpft die Erzählung ihre Kraft, ja die Gewalt eines mitreißenden Erzählens.

Ein letztes Mal keimt Hoffnung auf, als es Toni gelingt, Strömli und seine Gemeinschaft vor der Gefahr zu warnen und dazu zu bringen, zur Rettung von „Vetter August“ zu den Waffen zu greifen und zum Haus zu eilen. ${ }^{138}$ Die oft debattierte $^{139}$ Verdoppelung von Gustavs Namen in August zeigt dasselbe Oszillieren zwischen zwei Namensgebungen an, das sich bereits im Titelfraktal ausmachen ließ. Der hybriden Zweiteilung der Insel entspricht die Zweiteilung eines Menschen, der Toni - aber auch dem Leser - während dieser Phase höchster Anspannung und Gefahr in anderer, in seinem Lebenswissen zutiefst verwirrter Form entgegentreten wird.

Denn war Gustav trotz anfänglichen Zögerns Toni zugetan und zu ihrem Bräutigam geworden, so wird er sich nun als dummer, Tonis List nie wirklich durchschauender August aufführen, auch wenn er noch immer mit Gustav das etymologisch auf das Lateinische zurückgehende und damit das Französische und

135 Ebda., S. 72.

136 Vgl. zur Konstellation von Konvivenz und Katastrophe auch den Band von Ette, Ottmar / Kasper, Judith (Hg.): Unfälle der Sprache. Literarische und philologische Erkundungen der Katastrophe. Wien - Berlin: Verlag Turia + Kant 2014.

137 Kleist, Heinrich von: Die Verlobung in St. Domingo, S. 73.

138 Ebda., S. 76.

139 Vgl. hierzu etwa Loster-Schneider, Gudrun: Toni, Babekan und Homi Bhabha? Zu Problemen kultureller und ästhetischer Hybridisierung in Heinrich von Kleists „Die Verlobung in St. Domingo“, S. 245 f. 
Spanische zusammenführende Lexem „gust“ teilt. Dieses verweist nicht zuletzt auf das Gefallen, auf den Geschmack, das sinnliche und ästhetische Erleben, das Gustav/August immer noch mit der bildschönen Mulattin verbindet. Doch rückt es in der Verdoppelung des Namens von der mit Majuskel geschriebenen Anfangsposition in eine mit Minuskel versehene Endposition, was auf grundlegende Umbesetzungen, ja eine gewisse Verkehrung aufmerksam macht. Der Traum von Konvivenz schlägt bald schon in die Katastrophe um. Hätte Gustav sie abwenden können, wäre er am Morgen seines Todes Gustav geblieben?

Die Eroberung und Besetzung des Hauses durch Strömlis kleine Truppe geht rasch vonstatten und hebt die Auseinandersetzung zwischen Schwarzen und Weißen im Mikrokosmos des Hauses von der individuellen auf die kollektive Ebene: Es ist der Kampf unauflösbar miteinander verfeindeter Gemeinschaften, in dem es die Seiten zu wählen gilt, da es keine Zwischentöne mehr gibt. Daher bezeichnet sich Toni gegenüber ihrer Mutter, von der sie als „Niederträchtige und Verrätherinn“ beschimpft wird, wie in einem Akt der Selbstenttarnung als eine Weiße, die mit dem jungen Schweizer „verlobt“ sei: ${ }^{140}$ „ich gehöre zu dem Geschlecht derer, mit denen ihr im offenen Kriege liegt, und werde vor Gott, dass ich mich auf ihre Seite stellte, zu verantworten wissen“. ${ }^{141}$ Es ist ein letztes verzweifeltes Lossagen von der Mutter, der eigenen Herkunft, um noch einmal neue Zukunft zu gewinnen.

$\mathrm{Zu}$ der bereits figural in den Gestalten der schwarzen Sklavin und der weißen Braut Mariane vorgezeichneten Katastrophe kommt es, als „Vetter August“142 wie er von den Protagonisten, aber auch vom Erzähler selbst nun immer wieder genannt wird - nach seiner Befreiung erstmals wieder Toni erblickt und „bei diesem Anblick die Farbe“ wechselt. ${ }^{143}$ Nur wenige Sekunden später wird der von Strömli und seinen Söhnen als „ungeheurer Mensch“ (und damit als Zwitterwesen $^{144}$ zwischen Ungeheuer und Mensch) bezeichnete August „knirschend vor Wuth“ die schöne Mulattin durch einen Pistolenschuss „mitten durch die Brust“ töten. ${ }^{145} \mathrm{Zu}$ spät erfährt August von seinen Reisegefährten, dass die junge Mulattin bereit gewesen wäre, „mit ihm, dem sie Alles, Eltern und Eigenthum, aufgeopfert, nach Port au Prince zu entfliehen“. ${ }^{146}$ Hätte August ihre List begriffen, mit der sie

140 Kleist, Heinrich von: Die Verlobung in St. Domingo, S. 81.

141 Ebda., S. $81 \mathrm{f}$.

142 Ebda., S. 83.

143 Ebda., S. 84.

144 Auf die Wichtigkeit von Zwitterwesen macht u. a. aufmerksam Blamberger, Günter: Heinrich von Kleist. Biographie. Frankfurt am Main: S. Fischer 2011, S. 434.

145 Kleist, Heinrich von: Die Verlobung in St. Domingo, S. 84.

146 Ebda., S. 85. 
sich von ihrer Last, von ihrer Schuld am Tode anderer befreien wollte, so wäre es zwar nicht in der Karibik, wohl aber andernorts sehr wohl möglich geworden, den Traum von Konvivenz zumindest im fernen Europa in die Tat umzusetzen: Die Verlobung wäre zu einer Verheiratung geworden. Das Paradies war beinahe schon erreicht, doch kurz davor schlugen die Tore ein für alle Mal zu.

Der Katastrophe geht unmittelbar - wie wir gesehen haben - ein doppelter Farbenwechsel voraus. Während die Mulattin oder, wie sie mehrfach im Text ganz bewusst genannt wird, Mestize sich zur Weißen wandelt, wechselt Gustav seinen Namen nicht nur in August, sondern auch seine Farbe. Der Erzähler verrät seinen Lesern nicht, in welche Farbe der junge weiße Offizier wechselt: Ist es das Rot der Wut, das Gelb des oszillierenden ,Dazwischen“ und der Eifersucht oder das Schwarz des Todes? In jedem Falle ist der Wechsel doppelt todbringend. Denn als man ihm nun seinen alten Namen Gustav „in die Ohren“ donnert ${ }^{147}$ und sich die sterbende Toni gegen den Vorwurf des Verrats verwahrt, erhebt sich „Vetter Gustav“148 wieder von seinem Bett, legt noch einmal „seine Arme um ihren Leib“ und nimmt „mit jammervoll zerrissenem Herzen“ ihre letzten Worte entgegen: „,du hättest mir nicht mißtrauen sollen!““. ${ }^{149}$ Als Toni „ihre schöne Seele“ aushaucht ${ }^{150}$ und bereits „Zu besseren Sternen entflohn“ ist, ${ }^{151}$ jagt sich der wieder zu Gustav Gewordene die Kugel mit einem rasch angesetzten Mundschuss „durchs Hirn“. ${ }^{152}$ Zweimal war Gustav, der dumme August, verlobt - und zweimal hat er über seine bildhübschen Bräute Verderben gebracht.

Der finale Selbstmord, in dessen literarischer Inszenierung ${ }^{153}$ die KleistForschung schon oft die Vorwegnahme des eigenen Freitods gemeinsam mit der unheilbar erkrankten Henriette Vogel am 21. November 1811 am Kleinen Wannsee sah, lässt in der Katastrophe selbst die zum Greifen nahe Möglichkeit der Konvivenz aufscheinen. Tonis und Gustavs Hände verfehlen sich ein letztes Mal, zeigen in dieser letzten Bewegung aber auf, wie nahe sie einer Vereinigung gekommen waren: Fast hätten sich beide Seiten des Atlantiks doch noch vereinigt.

\footnotetext{
147 Ebda.

148 Ebda., S. 86.

149 Ebda., S. 87.

150 Ebda.

151 Ebda., S. 88.

152 Ebda., S. 88.

153 Vgl. hierzu auch das Kapitel „Ökonomie und Anökonomie des Opfers - Kleists letzte Inszenierung: der Freitod am Wannsee“ in Blamberger, Günter: Heinrich von Kleist. Biographie, S. 450-468.
} 
Toni leiht dem Bild der schönen Seele einen schönen Körper, gewiss! ${ }^{154}$ Doch Gustav hätte diese Seele, diesen dreifach - als ,Farbige‘, als Frau und als Antillanerin - diskriminierten Körper über alle Rassenschranken hinweg in eine neue Welt geholt, die freilich in den europäischen Kolonien der Neuen Welt noch nicht zu finden war. Doch noch im Scheitern, noch im Sterben wird die Lebbarkeit, ja das Durchleben einer solchen Konvivenz ästhetisch eindrucksvoll affirmiert. Genau in dieser nur vorübergehenden Vision wird ein semantischer Kern der gesamten Erzählung eines auf allen Ebenen gescheiterten Zusammenlebens sichtbar.

Die abschließend getroffene und auch wechselseitig eingehaltene Vereinbarung zwischen Strömli und Congo Hoango, die als Geiseln für freies Geleit genommenen Kinder des Schwarzen in „Sainte Lüze“155 - auch dies selbstverständlich ein hybrides, gleichsam zweisprachiges Toponym - zurückzugeben, zeigt auf, wie sehr Verträge auf Vertrauensbasis möglich sind: auch dann, wenn es nur allererste Schritte auf einer kollektiven Ebene sind. Eine Ebene künftiger Verständigung jenseits des Hasses zeichnet sich ab.

Auf einer individuellen, die zentral gestellte Liebesgeschichte betreffenden Ebene öffnet sich das gescheiterte Projekt künftigen Zusammenlebens auf eine Projektion, die jenseits des irdischen Lebens ein Zusammenleben aufscheinen lässt, werden die Leichen von Toni und Gustav doch am Möwenweiher - ungeachtet ihrer unterschiedlichen Herkunft - in einem gemeinsamen Grab bestattet. Und dies erfolgt, nachdem man die Ringe an ihren Händen gewechselt hatte, sie mithin symbolisch noch post mortem miteinander vermählte. Die Gräber der beiden Liebenden verwandeln sich in „die Wohnungen des ewigen Friedens“, wobei der Ort dieses friedlichen Zusammenlebens in Differenz nun ein Anderort, eine Heterotopie ist, so dass die Konvivenz in eine Transzendenz verlagert und übersetzt wird. Doch immerhin: Die beiden Liebenden sind nun Mann und Frau!

Die Flucht nach Port-au-Prince, die Rettung (nach der Eroberung der Stadt durch Dessalines) auf die Schiffe der (logischerweise) englischen Flotte, die Überfahrt nach Europa und die Heimkehr in die Schweiz beenden wie im Zeitraffer eine in ihren narrativen Verfahren ausgeklügelte Erzählung. Diese klingt nicht in Gustavs Schweizer Idylle, wohl aber in der Familie des Herrn Strömli aus. Die letzten Worte der Erzählerfigur gelten jenem Denkmal, das der wackere Strömli „Gustav, seinem Vetter, und der Verlobten desselben, der treuen Toni“, errichten

154 Vgl. hierzu Weigel, Sigrid: Der Körper als Kreuzpunkt von Liebesgeschichte und Rassendiskurs in Heinrich von Kleists Erzählung „Die Verlobung in St. Domingo“, S. 212.

155 Kleist, Heinrich von: Die Verlobung in St. Domingo, S. 90.

156 Ebda. 
ließ und das man „noch im Jahr 1807“ auf dem Anwesen in der Schweiz habe sehen können. ${ }^{157}$

Dass man das Denkmal noch im Jahre 1807 dort finden konnte, macht angesichts der wenigen Jahre, die seit den berichteten Ereignissen vergangen sind, erzähltechnisch im Grunde wenig Sinn. Entscheidend vielmehr ist, dass diese Jahreszahl auf ein bereits genanntes Biographem, auf Heinrich von Kleists direkte Bekanntschaft als Häftling mit jener Jurafestung Forteresse de Joux verweist, deren Kerker für Toussaint-L'Ouverture zum eiskalten, unmenschlichen Grab geworden war. So wird in das Denkmal für Toni und Gustav ein nicht weniger literarisches Denkmal für eine der großen Figuren der Haitianischen Revolution eingeblendet, gleichsam die Vorwegnahme einer Gedenktafel, wie wir sie heute vor jener Festung an der Schweizer Grenze finden. Noch 1807 hätte sie dort niemand anzubringen gewagt.

Heinrich von Kleists bis heute faszinierende Erzählung Die Verlobung in St. Domingo entfaltet ausgehend von ihrem Titelfraktal ein vielstimmiges und mehr noch viel-logisches Lebenswissen. Es tritt uns dank raffinierter Erzählkunst als ein Erlebenswissen entgegentritt, welches das Überlebenswissen wie das Zusammenlebenswissen eines Zeitraums präsentiert, der in der zweiten Phase beschleunigter Globalisierung durch den Zusammenbruch eines überkommenen, auf Sklaverei und damit extremer Ungleichheit und Ausbeutung beruhenden Zusammenlebens gekennzeichnet war. Dieses System wurde durch die Haitianische Revolution hinweggefegt.

Im Kollaps einer nicht mehr tragfähigen rassistischen Konvivenz entfaltet die Erzählung die Diegese einer Neuen Welt, in der sich neben den Zeichen der Zerstörung erste Anzeichen eines künftigen friedvollen Zusammenlebens andeuten beziehungsweise erkennen lassen. Hatte nicht Simón Bolívar, der selbst Anfang des Jahres 1816 auf seiner Flucht im Freiheitskampf Zuflucht in Haiti hatte suchen müssen, von der karibischen Nachbarinsel Jamaica aus in seiner berühmten Carta de Jamaica 1815 das intermediäre ZwischenWeltenLeben für die Neue Welt als bestimmend reklamiert? So betonte der „Libertador“, sich an die Bewohner seines Amerika - die eine „kleine Menschheit“ für sich darstellten - richtend, dass „wir weder Indianer noch Europäer sind, sondern eine mittlere Spezies zwischen den rechtmäßigen Eigentümern des Landes und den spanischen Usurpatoren: dass wir folglich Amerikaner von Geburt und unsere Rechte die von Europa sind“. ${ }^{158}$ Doch werden wir uns erst etwas später mit den Vertretern dieser Unabhängig-

157 Ebda.

158 Bolívar, Simón: Carta de Jamaica. The Jamaica Letter. Lettre à un Habitant de la Jamaïque. Caracas: Ediciones del Ministerio de Educación 1965, S. 69 (Übersetzung O.E.). 
keitsrevolution des künftigen Lateinamerika beschäftigen und sehen, in welchem Zusammenhang diese Ereignisse mit der aufkommenden Romantik auf dem amerikanischen Kontinent stehen.

Heinrich von Kleist hat in den Figuren seiner Erzählung, besonders aber in der als Mestizin bezeichneten Mulattin Toni jenes Oszillieren zwischen verschiedenen Welten gezeichnet, das gerade für die Karibik, für jene Zone verdichtetster Globalisierung, seit dem Beginn der europäischen Kolonisierung so charakteristisch ist. Er zeichnete damit nicht zufällig jenen Bewegungsraum zwischen zwei Welten vor, in welchem sich unsere Vorlesung bereits bewegt. Aus europäischer Sicht hat dieses Oszillieren, dieses ständige Wechseln der ,Farbe‘, seit jeher für Argwohn gesorgt. Ist Gustav nicht daran gescheitert, dass er die schöne Mulattin entweder den Schwarzen oder den Weißen, nicht aber einer unabschließbaren Bewegung im Zwischenraum zurechnen wollte? Scheiterte Gustav nicht an seiner Suche nach einer eindeutigen Identität für Toni, an seiner selbstgestellten Frage „Wer bist Du“?

In Tonis letzten, an ,ihren‘ Gustav gerichteten Worten, in jenem ,,du hättest mir nicht mißtrauen sollen! ““, ${ }^{159}$ wird sicherlich keine simplistische Moral aus der Geschichte gezogen, wohl aber jenes Lexem betont, das in der Rede von der ,treuen Toni “ ${ }^{160}$ in den letzten Worten des Erzählers noch einmal widerhallt. Gewiss hat sie sich auf die Seite der Weißen geschlagen, gewiss hat sie den Weg nach Europa, wo sie gezeugt und geboren wurde, ${ }^{161}$ gewählt, und gewiss scheint die gesamte Erzählung in der idyllischen „Gegend des Rigi“162 zur Ruhe zu kommen. Doch die unterschiedlichen, widersprüchlichen und oft antagonistischen zeitgenössischen Diskurse, die Heinrich von Kleist in seine Erzählung einzuweben verstand, machen diese zum Erprobungsraum einer möglichen Konvivenz, in deren Scheitern ein Wissen vom künftigen Zusammenleben aufscheint - auch wenn es in seiner Erzählung selbst nach dem Tod der beiden Liebenden angesiedelt ist.

Wenn alle Literatur ein Schreiben und damit Leben nach dem Paradies ist, ${ }^{\mathbf{1 6 3}}$ dann ließen sich Kleists Überlegungen aus seinem berühmten Essay Über das Marionettentheater sehr wohl auf jene Erzählung beziehen. Diese näherte sich diegetisch mit der Haitianischen Revolution nicht nur dem zeitgenössischen Paradigma und damit der Frage nach dem Zusammenleben, sondern auch jener

159 Kleist, Heinrich von: Die Verlobung in St. Domingo, S. 87.

160 Ebda., S. 91.

161 Ebda., S. 20.

162 Ebda., S. 91.

163 Vgl. hierzu u. a. das Eröffnungskapitel in Ette, Ottmar: Konvivenz. Literatur und Leben nach dem Paradies. 
Region an, in der Christoph Kolumbus einst das irdische Paradies vermutet hatte. Heinrich von Kleists Schreiben weiß davon, dass nach Adam und Evas Vertreibung und damit nach einer ersten Anwendung körperlicher Gewalt in der menschheitsgeschichtlichen Fiktion der Genesis die Rückkehr nach Eden verboten ist und für alle Zeiten als ein undurchführbares Vorhaben erscheint. Die Literatur aber hat im Sinne von Kleist noch nicht alle Hoffnung fahren lassen: „Doch das Paradies ist verriegelt und der Cherub hinter uns; wir müssen die Reise um die Welt machen und sehen, ob es vielleicht von hinten irgendwo wieder offen ist" ${ }^{164}$ Wir werden im weiteren Verlauf unserer Vorlesung noch auf so manche literarische Ausgestaltung des Irdischen Paradieses und so manchen Paradiessucher treffen, den wir auf seiner Suche begleiten wollen.

164 Kleist, Heinrich von: Über das Marionettentheater. In (ders.): Sämtliche Werke und Briefe in vier Bänden, Bd. III, S. 559. 